Article

\title{
Enhanced and Selective Antiproliferative Activity of Methotrexate-Functionalized-Nanocapsules to Human Breast Cancer Cells (MCF-7)
}

\author{
Catiúscia P. de Oliveira ${ }^{1}$, Sabrina L. Büttenbender ${ }^{2}$, Willian A. Prado ${ }^{2}$, Aline Beckenkamp ${ }^{1}$, \\ Ana C. Asbahr ${ }^{3}$ (D), Andréia Buffon ${ }^{1}$, Silvia S. Guterres ${ }^{1,3}$ and Adriana R. Pohlmann 1,2,3,* (D) \\ 1 Programa de Pós-Graduação em Ciências Farmacêuticas, Faculdade de Farmácia, Universidade Federal do \\ Rio Grande do Sul, Porto Alegre 90610-000, RS, Brazil; catipadilha@yahoo.com.br (C.P.d.O.); \\ alinee-b@hotmail.com (A.B.); andreia.buffon@ufrgs.br (A.B.); silvia.guterres@ufrgs.br (S.S.G.) \\ 2 Programa de Pós-Graduação em Química, Departamento de Química Orgânica, Instituto de Química, \\ Universidade Federal do Rio Grande do Sul, Porto Alegre 91501-970, RS, Brazil; \\ sbuttenbender@gmail.com (S.L.B.); will_ap20@hotmail.com (W.A.P.) \\ 3 Programa de Pós-Graduação em Nanotecnologia Farmacêutica, Universidade Federal do Rio Grande do Sul, \\ Porto Alegre 90610-000, RS, Brazil; acasbahr@hotmail.com \\ * Correspondence: adriana.pohlmann@ufrgs.br; Tel.: +55-51-3308-7237
}

Received: 3 November 2017; Accepted: 28 December 2017; Published: 4 January 2018

\begin{abstract}
Methotrexate is a folic acid antagonist and its incorporation into nanoformulations is a promising strategy to increase the drug antiproliferative effect on human breast cancer cells by overexpressing folate receptors. To evaluate the efficiency and selectivity of nanoformulations containing methotrexate and its diethyl ester derivative, using two mechanisms of drug incorporation (encapsulation and surface functionalization) in the in vitro cellular uptake and antiproliferative activity in non-tumoral immortalized human keratinocytes $(\mathrm{HaCaT})$ and in human breast carcinoma cells (MCF-7). Methotrexate and its diethyl ester derivative were incorporated into multiwall lipid-core nanocapsules with hydrodynamic diameters lower than $160 \mathrm{~nm}$ and higher drug incorporation efficiency. The nanoformulations were applied to semiconfluent HaCaT or MCF-7 cells. After $24 \mathrm{~h}$, the nanocapsules were internalized into HaCaT and MCF-7 cells; however, no significant difference was observed between the nanoformulations in HaCaT (low expression of folate receptors), while they showed significantly higher cellular uptakes than the blank-nanoformulation in MCF-7, which was the highest uptakes observed for the drug functionalized-nanocapsules. No antiproliferative activity was observed in $\mathrm{HaCaT}$ culture, whereas drug-containing nanoformulations showed antiproliferative activity against MCF-7 cells. The effect was higher for drug-surface functionalized nanocapsules. In conclusion, methotrexate-functionalized-nanocapsules showed enhanced and selective antiproliferative activity to human breast cancer cells (MCF-7) being promising products for further in vivo pre-clinical evaluations.
\end{abstract}

Keywords: methotrexate; surface functionalized lipid-core nanocapsules; breast cancer; cellular uptake; antiproliferative activity

\section{Introduction}

Nanocarrier drug delivery systems are very promising strategies for the treatment of tumors leading to improved therapeutic efficacy [1-3] and reduced drug doses [4,5]. The incorporation of drugs into nanocarriers can be performed by either encapsulation or surface functionalization [6-8]. Drug-loaded nanoparticles accumulate at the target tissues or organs due to diverse factors, such as permeability of barriers, tissue damage and $\mathrm{pH}$ environment $[9,10]$. Active cellular targeting can 
be achieved by functionalizing the surface of nanoparticles with ligands that promote cell-specific recognition and binding, increasing the treatment specificity [11-13]. Among the targets, there is the folate receptor $[13,14]$, which is present in the cell membrane and participates in the process of cell replication [15]. Tumor cells replicate more rapidly than normal cells expressing high level of folate receptors. In this sense, the functionalization of nanoparticles with folic acid, or its antagonists, constitutes a promising strategy to improve the efficacy and the selectivity of breast cancer treatment [16-18].

Methotrexate is a folic acid antagonist and acts as a ligand for the folate receptor. The incorporation of this drug into nanocarrier systems is an interesting approach, since it increases the drug antiproliferative action [18], improves the specificity for the organ or target tissue [19] and increases the anti-inflammatory action [20]. Additionally, the cellular uptake of magnetic nanoparticles [21] conjugated with methotrexate has improved in either 10-times (HeLa) or 20-times (MCF-7), compared to cells with low expression of folate receptor, such as cardiomyocytes, demonstrating higher specificity. However, as methotrexate is a drug with low lipophilicity, encapsulation in organic and biodegradable nanoparticles becomes difficult. Some alternatives are either the derivatization of the molecule, making it more lipophilic without losing the biological activity [22] or its use as ligand to functionalize the surface of the nanocarrier systems, as we have previously proposed for an antibody fragment [23]. Functionalization is based on the formation of an organometallic complex on the nanoparticle surface, using chitosan-coated lipid-core nanocapsules as nanocarriers, zinc (II), as metal ion and a molecule containing oxygen and/or nitrogen atoms, as ligand. The transition metal ion forms a chelate with chitosan and ligand on the nanoparticle surface [24]. We hypothesized that methotrexate, which contains amino acid functional groups, could be an effective ligand to functionalize the surface of those nanocapsules. Furthermore, this molecule could be incorporated into the nanocapsules by two mechanisms: encapsulation or surface functionalization, influencing the antiproliferative action of nanoformulations.

Breast cancer is the most common cancer in women [25,26]. Advances in cancer treatment have been improving the survival rates of patients. However, cancer is a heterogeneous disease [27] and the treatment involves multiple drugs that may cause many adverse effects $[28,29]$. Therefore, cancer cells can develop resistance to drugs and methotrexate resistance has been well documented [30,31]. Therefore, it is necessary to develop alternative drug delivery systems in order to improve therapeutic efficacy. Recently, we have showed that methotrexate-diethyl ester-loaded lipid-core nanocapsules increased antineoplastic effects on resistant breast cancer cell line [22].

Thus, an anti-tumor activity could be improved by functionalizing the surface of multiwall lipid-core nanocapsules with methotrexate taking advantage of its ability to interact with the folate receptor and to act as an antiproliferative agent. Considering the physicochemical characteristics of methotrexate, our first step was to synthesize three different multiwall lipid-core nanocapsules (MLNC). The first one was prepared using methotrexate incorporated by encapsulation and by surface functionalization (organometallic complex) (MTX-Zn-MLNC-MTX); the other two formulations were prepared using methotrexate diethyl ester, a more lipophilic drug derivative, by encapsulation into the nanocapsules [Phe-Zn-MLNC-MTX $(\mathrm{OEt})_{2}$ ] or by surface functionalization [MTX $(\mathrm{OEt})_{2}$-Zn-MLNC] (Figure 1). The formulations were evaluated considering their cellular uptake and in vitro antiproliferative activity in non-tumoral immortalized human keratinocytes (HaCaT) with low expression of folate receptors and in human breast carcinoma cells (MCF-7), which overexpress folate receptors. 

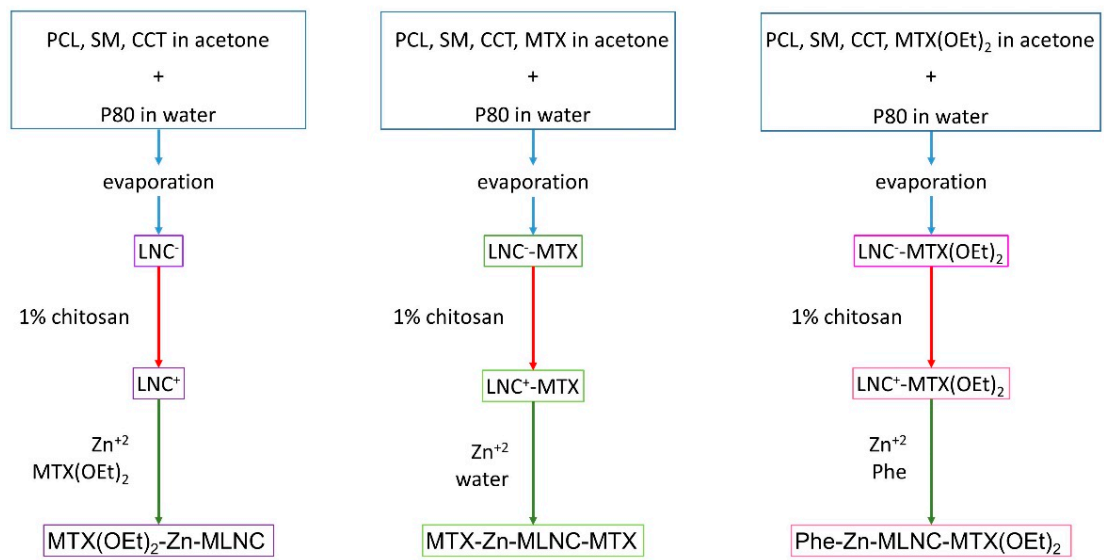

Figure 1. Scheme of synthesis: lecithin-polysorbate 80-coated lipid-core nanocapsules $\left(\mathrm{LNC}^{-}\right)$ containing or not drug, methotrexate (MTX) or methotrexate diethyl ester [MTX $(\mathrm{OEt})_{2}$ ], prepared using poly ( $\varepsilon$-caprolactone) (PCL), sorbitan monostearate (SM) and capric-caprylic triglyceride (CCT), were reacted with $1 \%$ chitosan producing chitosan-lecithin-polysorbate 80 -coated lipid-core nanocapsules $\left[\mathrm{LNC}^{+}, \mathrm{LNC}^{+}-\mathrm{MTX}\right.$ or $\left.\mathrm{LNC}^{+}-\mathrm{MTX}(\mathrm{OEt})_{2}\right]$, which were used to obtain multiwall lipid-core nanocapsules (MLNC) complexed with $\mathrm{Zn}^{2+}$ and (i) methotrexate diethyl ester [MTX(OEt) $)_{2}$-Zn-MLNC]; (ii) encapsulated and functionalized methotrexate (MTX-Zn-MLNC-MTX); and (iii) methotrexate diethyl ester-encapsulated in the multiwall lipid-core nanocapsules which surface is passivate with phenylalanine [Phe-Zn-MLNC-MTX(OEt $\left.)_{2}\right]$.

\section{Results}

\subsection{Synthesis of Functionalized-Zn-MLNC Formulations}

The nanoformulations were prepared containing $\operatorname{MTX}$ or MTX $(\mathrm{OEt})_{2}$, as described above. Considering the experimental procedures to obtain the nanoformulations, as well as the lipophilicity of MTX or MTX $(\mathrm{OEt})_{2}$ in the LNC-environment (log D of -2.4 and 2.2, respectively), we proposed the supramolecular structural models for each nanocapsule (Figure 2). MTX(OEt) 2 -Zn-MLNC was obtained from drug-unloaded lipid-core nanocapsules coated with lecithin-chitosan-polysorbate 80 and its surface was reacted with $\mathrm{Zn}^{2+}$ and methotrexate diethyl ester. MTX-Zn-MLNC-MTX was formed from a dispersion of nanocapsules partially encapsulating MTX and its surface was coated with lecithin-chitosan-polysorbate 80. The $\mathrm{LNC}^{+}-\mathrm{MTX}$ was reacted with $\mathrm{Zn}^{2+}$, which caused the complexation of methotrexate initially soluble in the continuous phase of LNC-MTX. The third formulation, Phe-Zn-MLNC-MTX $(\mathrm{OEt})_{2}$ was obtained from MTX $(\mathrm{OEt})_{2}$-loaded lipid-core nanocapsules coated with lecithin-chitosan-polysorbate 80 , which surface is reacted with $\mathrm{Zn}^{2+}$ and phenylalanine. The formulations were prepared in triplicate. Intermediate product, lipid-core nanocapsules coated with chitosan-lecithin-polysorbate $80\left(\mathrm{LNC}^{+}\right)$and a second blank-formulation (Phe-Zn-MLNC) were also prepared as control groups in cell viability studies.

Blank-nanoformulations ( $\mathrm{LNC}^{+}$and Phe-Zn-MLNC), prepared without drug, showed homogeneous white opalescent macroscopic aspect, while the nanoformulations prepared with MTX and MTX(OEt) $)_{2}$ [Phe-Zn-MLNC-MTX(OEt) $)_{2}$, MTX $(\mathrm{OEt})_{2}-Z n-M L N C$ and MTX-Zn-MLNC-MTX] had yellowish opalescent macroscopic aspect (data not shown). In parallel, rhodamine B-labeled formulations were prepared using PCL-RhoB conjugate blended with PCL [f-LNC ${ }^{+}$, f-Phe-Zn-MLNC-MTX(OEt) $)_{2}$, f-MTX(OEt $)_{2}-Z n-M L N C$ and f-MTX-Zn-MLNC-MTX], exhibiting macroscopic homogenous pink whitish aspect (data not shown). The formulations presented $\mathrm{pH}$ values (without dilution) between $3.60 \pm 0.08$ and $4.24 \pm 0.15$ due to the presence of acetic acid used to disperse chitosan in aqueous medium. One batch of a double-fluorescent-labeled formulation (ff-MTX-Zn-MLNC-MTX) was prepared using PCL-RhoB, a polymer conjugate and 5AHBO-C8, a highly lipophilic benzoxazole dye derivative. PCL-RhoB was blended with PCL at the polymer 
wall and 5AHBO-C8 was dispersed with sorbitan monostearate in MCT oil. This strategy was used to investigate the co-localization of both lipophilic domains of the nanocapsules (lipid-core and polyester wall) in the cellular uptake study. Laser diffraction analysis was used to determine the characteristic size distribution curves and to investigate if the formulations were contaminated by microaggregates or microparticles. All size distribution profiles presented exclusively submicrometric particle populations. Blank-nanoformulations ( $\mathrm{LNC}^{+}$and Phe-Zn-MLNC) and drug-contained nanoformulations [Phe-Zn-MLNC-MTX(OEt) $)_{2}, \mathrm{MTX}(\mathrm{OEt})_{2}-\mathrm{Zn}-\mathrm{MLNC}$ and MTX-Zn-MLNC-MTX] had unimodal diameter distribution showing volume-weighted mean diameters (D[4,3]) smaller than $135 \pm 10 \mathrm{~nm}$, with polydispersity (SPAN) below $1.1 \pm 0.1$. The specific surface area (SA) of nanocapsules ranged from $52 \pm 1$ to $56 \pm 5 \mathrm{~m}^{2} \cdot \mathrm{g}^{-1}$ (Table 1). Regarding the fluorescent-labeled formulations, the laser diffraction analysis showed D[4,3] smaller than $190 \mathrm{~nm}$ (Table 2).
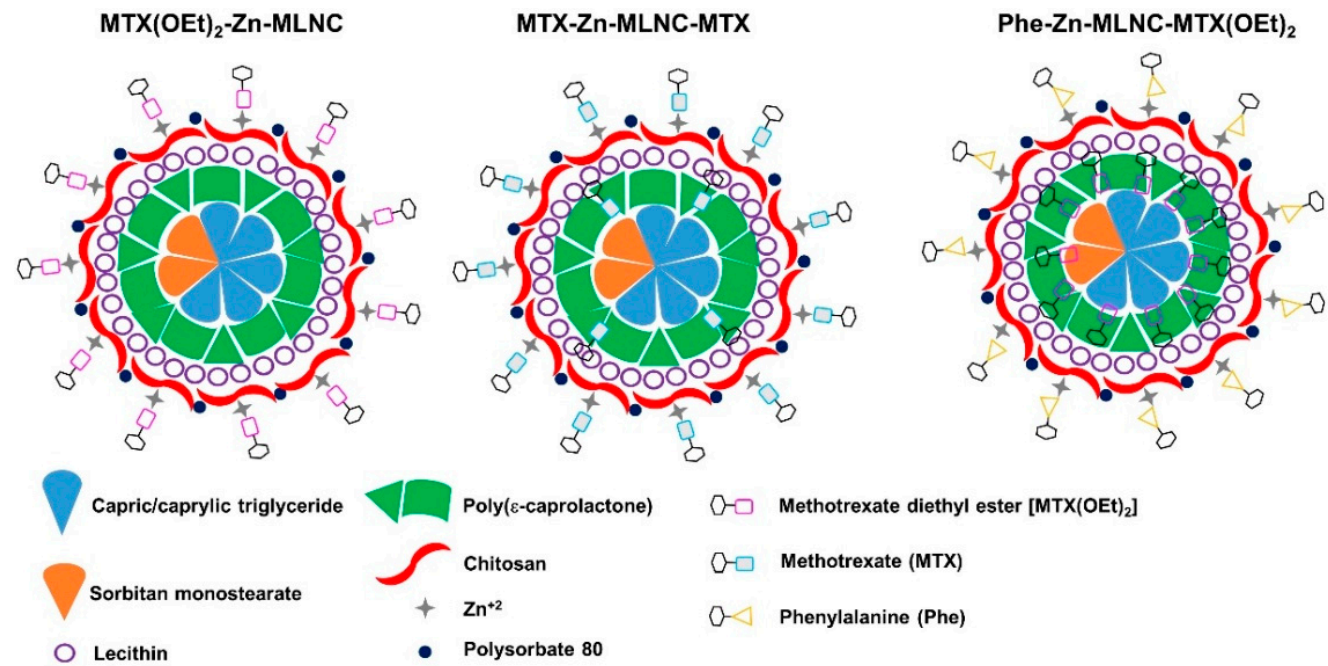

Lecithin

- Polysorbate 80

Figure 2. Illustrative models for the supramolecular structures of MTX(OEt $)_{2}-\mathrm{Zn}-\mathrm{MLNC}$, MTX-Zn-MLNC-MTX and Phe-Zn-MLNC-MTX(OEt) $)_{2}$.

Table 1. Physicochemical characterization of $\mathrm{LNC}^{+}$, Phe-Zn-MLNC, Phe-Zn-MLNC-MTX(OEt) ${ }_{2}$, MTX(OEt $)_{2}$-Zn-MLNC and MTX-Zn-MLNC-MTX formulations.

\begin{tabular}{|c|c|c|c|c|c|}
\hline & $\mathrm{LNC}^{+}$ & Phe-Zn-MLNC & Phe-Zn-MLNC-MTX $(\mathrm{OEt})_{2}$ & MTX $(\mathrm{OEt})_{2}$-Zn-MLNC & MTX-Zn-MLNC-MTX \\
\hline $\mathrm{D}[4,3](\mathrm{nm})$ & $126 \pm 3$ & $125 \pm 6$ & $135 \pm 10$ & $125 \pm 3$ & $131 \pm 3$ \\
\hline Span & $0.9 \pm 0.1$ & $1.0 \pm 0.2$ & $1.1 \pm 0.1$ & $0.8 \pm 0.0$ & $1.0 \pm 0.1$ \\
\hline $\mathrm{SA}\left(\mathrm{m}^{2} \mathrm{~g}^{-1}\right)$ & $53 \pm 1$ & $56 \pm 5$ & $53 \pm 2$ & $53 \pm 1$ & $52 \pm 1$ \\
\hline $\mathrm{D}_{z-a v e}(\mathrm{~nm})$ & $130 \pm 4$ & $134 \pm 10$ & $160 \pm 32$ & $148 \pm 33$ & $144 \pm 9$ \\
\hline PDI & $0.16 \pm 0.03$ & $0.17 \pm 0.03$ & $0.13 \pm 0.03$ & $0.14 \pm 0.04$ & $0.16 \pm 0.03$ \\
\hline $\mathrm{DC}(\mathrm{g} / \mathrm{L})$ & $(3.6 \pm 0.01) \times 10^{-10}$ & $(3.5 \pm 0.02) \times 10^{-10}$ & $(3.0 \pm 0.06) \times 10^{-10}$ & $(3.2 \pm 0.06) \times 10^{-10}$ & $(3.2 \pm 0.02) \times 10^{-10}$ \\
\hline$\zeta$ Potential $(\mathrm{mV})$ & $+14 \pm 3$ & $+18 \pm 5$ & $+14 \pm 4$ & $+17 \pm 5$ & $+18 \pm 7$ \\
\hline $\mathrm{D}_{h}(\mathrm{~nm})$ & & $143 \pm 10$ & $140 \pm 9$ & $141 \pm 12$ & $176 \pm 13$ \\
\hline D50 (nm) & & $133 \pm 8$ & $136 \pm 12$ & $131 \pm 6$ & $160 \pm 11$ \\
\hline $\mathrm{D} 90(\mathrm{~nm})$ & & $185 \pm 8$ & $194 \pm 6$ & $190 \pm 3$ & $243 \pm 11$ \\
\hline $\operatorname{PND}\left(\times 10^{12}\right.$ particles $\left.\mathrm{mL}^{-1}\right)$ & & $5.7 \pm 0.9$ & $4.7 \pm 0.5$ & $5.3 \pm 0.8$ & $5.7 \pm 0.1$ \\
\hline$\left[\mathrm{Zn}^{2+}\right]\left(\mu \mathrm{g} \cdot \mathrm{mL}^{-1}\right)$ & - & $76 \pm 9$ & $86 \pm 2$ & $96 \pm 9$ & $99 \pm 3$ \\
\hline$\left[\right.$ Drug] $\left(\mu \mathrm{g} \cdot \mathrm{mL}^{-1}\right)$ & - & - & $115 \pm 4$ & $113 \pm 3$ & $101 \pm 3$ \\
\hline $\mathrm{E} \%$ & - & - & $99 \pm 1$ & $97 \pm 5$ & $94 \pm 6$ \\
\hline
\end{tabular}

Note: Data are expressed as mean \pm standard deviation. Abbreviations: $\mathrm{LNC}^{+}$, lipid-core nanocapsules; Phe-Zn-MLNC multiwall lipid-core nanocapsules; Phe-Zn-MLNC-MTX $(\mathrm{OEt})_{2}$, multiwall methotrexate ester-loaded lipid-core nanocapsules; MTX $(\mathrm{OEt})_{2}$-Zn-MLNC, methotrexate ester-functionalized multiwall lipid-core nanocapsules; MTX-Zn-MLNC-MTX, methotrexate-functionalized methotrexate-loaded multiwall lipid-core nanocapsules; $\mathrm{D}[4,3]$, volume-weighted mean diameter; $\mathrm{SA}$, surface area; $\mathrm{D}_{z-a v e}$, hydrodynamic diameter by DLS; PDI, polydispersion index; DC, diffusion coefficient; $\mathrm{D}_{h}$, hydrodynamic diameter by NTA; D50, median diameter; D90, diameter at $90 \%$ under the size distribution curve; PND, particles number density; $\left[\mathrm{Zn}^{2+}\right]$, concentration of zinc-II; [Drug], concentration of methotrexate or methotrexate ester; E\%, incorporation efficiency. 
Table 2. Physicochemical characterization of fluorescent-labeled formulations, f-LNC ${ }^{+}$, f-Phe-ZnMLNC-MTX(OEt) ${ }_{2}$, f-MTX(OEt) ${ }_{2}$-Zn-MLNC, f-MTX-Zn-MLNC-MTX and ff-MTX-Zn-MLNC-MTX.

\begin{tabular}{|c|c|c|c|c|c|}
\hline & f-LNC ${ }^{+}$ & f-Phe-Zn-MLNC-MTX(OEt $)_{2}$ & f-MTX(OEt $)_{2}-\mathrm{Zn}-\mathrm{MLNC}$ & f-MTX-Zn-MLNC-MTX & ff-MTX-Zn-MLNC-MTX \\
\hline $\mathrm{D}[4,3](\mathrm{nm})$ & $173 \pm 69$ & $138 \pm 12$ & $156 \pm 33$ & $145 \pm 18$ & 190 \\
\hline Span & $1.3 \pm 0.5$ & $1.1 \pm 0.1$ & $1.2 \pm 0.1$ & $1.2 \pm 0.1$ & 1.1 \\
\hline $\mathrm{SA}\left(\mathrm{m}^{2} \mathrm{~g}^{-1}\right)$ & $49 \pm 4$ & $53 \pm 2$ & $53 \pm 2$ & $52 \pm 4$ & 53 \\
\hline Dz-ave (nm) & $153 \pm 25$ & $143 \pm 15$ & $158 \pm 20$ & $150 \pm 4$ & 144 \\
\hline PDI & $0.21 \pm 0.07$ & $0.18 \pm 0.01$ & $0.18 \pm 0.01$ & $0.19 \pm 0.01$ & 0.22 \\
\hline $\mathrm{DC}(\mathrm{g} / \mathrm{L})$ & $(3.1 \pm 0.05) \times 10^{-10}$ & $(3.3 \pm 0.03) \times 10^{-10}$ & $(3.0 \pm 0.03) \times 10^{-10}$ & $(3.0 \pm 0.01) \times 10^{-10}$ & $3.2 \times 10^{-10}$ \\
\hline$\zeta$ Potential $(\mathrm{mV})$ & $+17 \pm 3$ & $+17 \pm 1$ & $+20 \pm 6$ & $+18 \pm 2$ & +15 \\
\hline$\left[\mathrm{Zn}^{2+}\right]\left(\mu \mathrm{g} \cdot \mathrm{mL}^{-1}\right)$ & - & $90 \pm 5$ & $95 \pm 10$ & $100 \pm 3$ & 94 \\
\hline$[\operatorname{Drug}]\left(\mu \mathrm{g} \cdot \mathrm{mL}^{-1}\right)$ & - & $111 \pm 3$ & $112 \pm 6$ & $102 \pm 5$ & 107 \\
\hline $\mathrm{E} \%$ & - & $100 \pm 1$ & $96 \pm 4$ & $95 \pm 8$ & 96 \\
\hline
\end{tabular}

Note: Data are expressed as mean \pm standard deviation, except for ff-MTX-Zn-MLNC-MTX. Abbreviations: f-LNC ${ }^{+}$, fluorescent-labeled lipid-core nanocapsules; f-Phe-Zn-MLNC-MTX(OEt) ${ }_{2}$ fluorescent-labeled multiwall methotrexate ester-loaded lipid-core nanocapsules; f-MTX(OEt) $)_{2}$ Zn-MLNC, fluorescent-labeled methotrexate ester-functionalized multiwall lipid-core nanocapsules; f-MTX-Zn-MLNC-MTX, fluorescent-labeled methotrexate-functionalized methotrexate-loaded multiwall lipid-core nanocapsules; D[4,3], volume-weighted mean diameter; SA, surface area; $\mathrm{D}_{z-\text { ave }}$, hydrodynamic diameter by DLS; PDI, polydispersion index; DC, diffusion coefficient $\left[\mathrm{Zn}^{2+}\right]$, concentration of zinc-II; [Drug], concentration of methotrexate or methotrexate ester; E\%, incorporation efficiency.

Taking into account that the formulations did not show any microscopic contaminants and had exclusively size distribution profiles below $1 \mathrm{~mm}$, the dynamic light scattering (DLS) and the nanoparticle tracking analysis (NTA) were used. Those methods provided the size distribution profiles of samples based on the translational diffusion coefficient (Brownian motion of particles suspended in a fluid). All samples showed unimodal size distributions by DLS. The hydrodynamic diameters $\left(\mathrm{D}_{z-a v e}\right)$, calculated using the method of Cumulants, ranged from $144 \pm 9$ to $160 \pm 32 \mathrm{~nm}$ with polydispersity indexes (PDI) below 0.16 (Tables 1 and 2). The zeta potential varied from $+14 \pm 3$ to $+20 \pm 6 \mathrm{mV}$ (Tables 1 and 2). Using NTA, the hydrodynamic diameter $\left(\mathrm{D}_{h}\right)$ varied from $140 \pm 9$ to $176 \pm 13 \mathrm{~nm}$ for those nanoformulations. The diameter at percentile 90 under the size distribution curve ranged from $190 \pm 3$ to $243 \pm 11 \mathrm{~nm}$ and the particle number density ranged from $(4.7 \pm 0.5) \times 10^{12}$ to $(5.7 \pm 0.1) \times 10^{12}$ particles $\mathrm{mL}^{-1}$ (Table 1$)$.

The experimental concentration of zinc-II in the blank-formulation (Phe-Zn-MLNC) and in the drug-contained formulations (fluorescent-labeled or not) ranged from 76 to $100 \mathrm{mg} \cdot \mathrm{mL}^{-1}$ (Tables 1 and 2). Furthermore, the drug contents [concentrations of MTX or MXT(OEt $)_{2}$ ] varied from $101 \pm 3 \mu \mathrm{g} \cdot \mathrm{mL}^{-1}$ to $115 \pm 4 \mu \mathrm{g} \cdot \mathrm{mL}^{-1}$, with encapsulation efficiency higher than $94 \%$ (Tables 1 and 2).

\subsection{Cellular Uptake Studies}

The spontaneously immortalized human epithelial cell line (HaCaT) was studied as a model for the in vitro nanoparticle uptake by healthy cells (non-tumorigenic control cells). The volume of formulations applied to each well corresponds to a surface area of nanocapsule of $12 \mathrm{~cm}^{2} \cdot \mathrm{mL}^{-1}$ and to a concentration of MTX or MXT(OEt $)_{2}$ of $0.17 \mathrm{mmol} \cdot \mathrm{L}^{-1}$. The increase in the fluorescence intensity $(p<0.05)$ observed for the treatment groups compared to the control (untreated HaCaT cells) demonstrated the internalization of the nanocapsules (Figure 3a). The maximum fluorescence intensity determined for the group receiving $\mathrm{f}-\mathrm{LNC}^{+}$was used as reference of the nanocapsules uptake by the $\mathrm{HaCaT}$ cells. The maximum fluorescence intensity observed for the nanoformulations containing MTX and $\operatorname{MTX}(\mathrm{OEt})_{2}$ were similar to them and to the reference $\left(\mathbf{f}-\mathrm{LNC}^{+}\right)(p>0.05)$ (Figure $3 c$ ).

The cellular uptake study was also conducted using human breast carcinoma cells (MCF-7). Similar doses were applied to the cell culture (surface area of nanocapsule applied was $12 \mathrm{~cm}^{2} \cdot \mathrm{mL}^{-1}$; and MTX or its diethyl ester concentration was $0.17 \mathrm{mmol} \cdot \mathrm{L}^{-1}$ ). After $24 \mathrm{~h}$ of incubation, the MCF-7 nanocapsule uptake was assessed by flow cytometry (Figure 3b). All nanoformulations showed cellular uptake higher than the control group $(p<0.05)$. Additionally, the fluorescence intensity means, considering $\mathrm{f}-\mathrm{LNC}^{+}$as reference, demonstrated that $\mathrm{f}$-Phe-Zn-MLNC-MTX $(\mathrm{OEt})_{2}$, f-MTX $(\mathrm{OEt})_{2}$-Zn-MLNC and f-MTX-Zn-MLNC-MTX showed significantly higher $(p<0.05)$ nanocapsule cellular uptake than f-LNC ${ }^{+}$(Figure 3c). Furthermore, f-MTX $(\mathrm{OEt})_{2}-\mathrm{Zn}$-MLNC and f-MTX-Zn-MLNC-MTX promoted even higher nanocapsules uptake by MCF-7 cells $(p<0.05)$ 
compared to $\mathrm{f}-\mathrm{Phe}-\mathrm{Zn}-\mathrm{MLNC}-\mathrm{MTX}(\mathrm{OEt})_{2}$ because of the overexpression of folate receptors on the cellular surface.

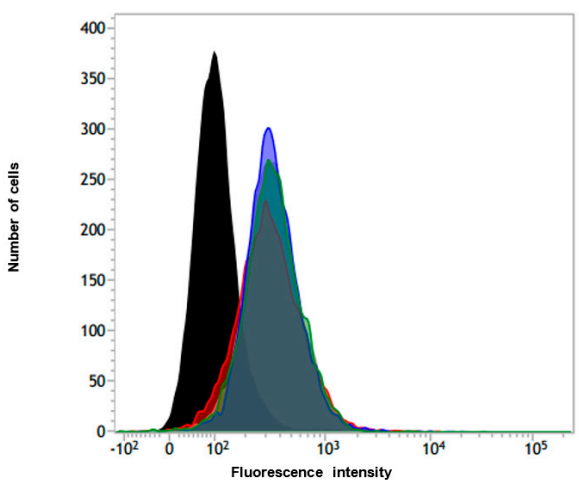

(a)

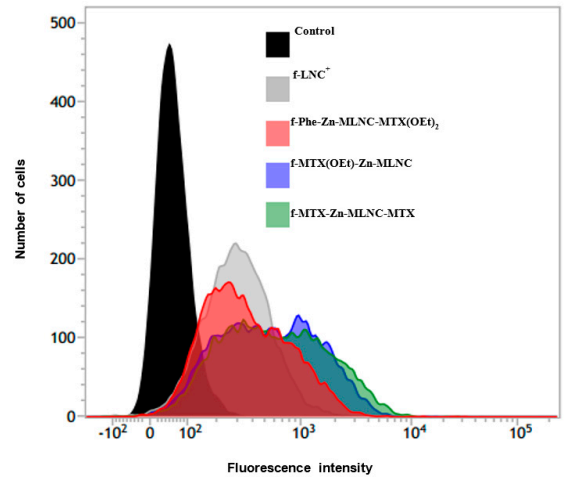

(b)

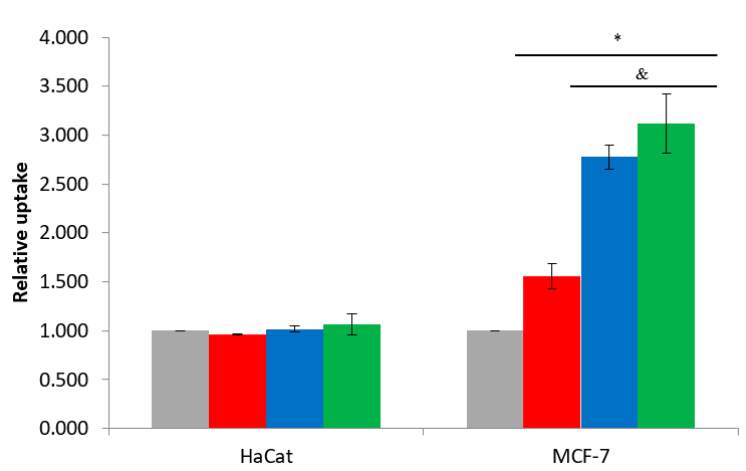

(c)

Figure 3. Flow cytometry plot showing the fluorescence intensity versus the number of cells for (a) HaCaT (spontaneously immortalized human epithelial cell line) and (b) MCF-7 (human breast carcinoma cells), in which the nanoformulations (color distributions) are compared $(p<0.05)$ to the control (untreated cells, black distribution); (c) Histogram of the relative cellular uptake for $\mathrm{f}-\mathrm{LNC}^{+}$ $(100 \%)$, f-Phe-Zn-MLNC-MTX(OEt) ${ }_{2}$, f-MTX(OEt) ${ }_{2}$-Zn-MLNC, f-MTX-Zn-MLNC-MTX. Data represent average $\pm \mathrm{SD}(n=3)$. No significant difference among formulations $(p>0.05)$ was determined for cellular uptake (ANOVA, Tukey). For MCF-7 cells, Phe, MTX and MTX $(\mathrm{OEt})_{2}$-surface functionalized nanoformulations showed higher nanocapsule cellular uptake than $\mathbf{f}-\mathrm{LNC}^{+}\left({ }^{*} p<0.05\right.$; ANOVA, Tukey). MTX and MTX $(\mathrm{OEt})_{2}$-surface functionalized nanoformulations showed higher nanocapsule cellular uptake than f-Phe-Zn-MLNC-MTX $(\mathrm{OEt})_{2}(\& p<0.05$; ANOVA, Tukey).

Confocal fluorescence microscopy was performed by analyzing MCF-7 cells after $24 \mathrm{~h}$ of incubation with the fluorescent-labeled-nanoformulations (supporting information Figure S1). First, the images were recorded without excitation using differential interface contrast (Figure S1, column 1). Next, the images were recorded using a $559 \mathrm{~nm}$ laser and a red fluorescence channel (Figure S1, column 2) showing red emission from the PCL-RhoB conjugate (nanocapsule polymeric wall). Nanocapsule cellular uptake by MCF-7 was determined for $\mathbf{f}-\mathrm{LNC}^{+}, \mathbf{f}-\mathrm{Phe}-\mathrm{Zn}-\mathrm{MLNC}-\mathrm{MTX}(\mathrm{OEt})_{2}$, f-MTX(OEt) $)_{2}$-Zn-MLNC and f-MTX-Zn-MLNC-MTX formulations after observing the merged images (Figure S1, column 3) by overlapping of channels (Figure S1, columns 1 and 2).

Confocal fluorescence microscopy analysis of MCF-7 incubated with the double-labeled formulation (ff-MTX-Zn-MLNC-MTX) was performed using differential interface contrast and two lasers for excitation at $405 \mathrm{~nm}$ (5AHBO-C8) and at $559 \mathrm{~nm}$ (PCL-RhoB) and the respective channels to record the images (supporting information Figure S2). Cells are shown in Figure S2a, 5AHBO-C8 blue emission in Figure S2b, PCL-RhoB red emission in Figure S2c and the merged image in Figure S2d. 
The double-labeled ff-MTX-Zn-MLNC-MTX uptake by MCF-7 cells was confirmed by observing the magenta secondary color corresponding to the co-localization of blue and red primary colors respectively emitted by 5AHBO-C8 and PCL-RhoB (Figure S2d). In addition, in Figure S2d, we also observed the cellular regions where the blue emission band was exclusively recorded, suggesting the release of 5AHBO-C 8 from the nanocapsules within the incubation period of time.

\subsection{In Vitro Cytotoxicity}

The cytotoxicity of the nanoformulations was evaluated using the MTT assay in both immortalized human keratinocyte line (HaCaT) and in human breast carcinoma cell line (MCF-7). Similar surface areas of nanocapsules were applied to compare the nanoformulations and the blank-nanoformulation. Equivalent dose was selected for the treatments corresponding to a nanocapsule surface area of $189 \mathrm{~cm}^{2} \cdot \mathrm{mL}^{-1}$. For the nanoformulations containing methotrexate or its diethyl ester, the applied area $\left(189 \mathrm{~cm}^{2} \cdot \mathrm{mL}^{-1}\right)$ was a dose equivalent to $2.74 \mathrm{mmol}$ of drug (or pro-drug) per liter of formulation. Therefore, for comparative purposes, the MTX and MTX $(\mathrm{OEt})_{2}$ solutions were applied at the same dose $\left(2.74 \mathrm{mmol} \cdot \mathrm{L}^{-1}\right)$.

In HaCaT cultures, the nanoformulations Phe-Zn-MLNC-MTX $(\mathrm{OEt})_{2}, \mathrm{MTX}(\mathrm{OEt})_{2}-\mathrm{Zn}-\mathrm{MLNC}$ and MTX-Zn-MLNC-MTX showed similar cell viability $(p>0.05)$ to Control 1 (DMEM) and the blank-nanoformulation $\left(\mathrm{LNC}^{+}\right)$(Figure 4$)$, whereas, in MCF-7 cultures, significant reductions $(p<0.05)$ in cell viability were observed when MTX and MTX $(\mathrm{OEt})_{2}$ solutions, as well as Phe-Zn-MLNC, Phe-Zn-MLNC-MTX(OEt) ${ }_{2}$, MTX(OEt $)_{2}$-Zn-MLNC and MTX-Zn-MLNC-MTX were applied (Figure 5). MTX $(\mathrm{OEt})_{2}$-Zn-MLNC and MTX-Zn-MLNC-MTX showed similar $(p>0.05)$ cytotoxic effects but much more pronounced than that observed for Phe-Zn-MLNC-MTX $(\mathrm{OEt})_{2}(p<0.05)$. Similar cell viability was observed for $\mathrm{LNC}^{+}$(blank formulation) and controls (DMEM or 0.1\% DMSO aqueous solution) $(p>0.05)$. Reduction of cell viability was significantly higher $(p<0.05)$ for Phe-Zn-MLNC-MTX $(\mathrm{OEt})_{2}$, MTX $(\mathrm{OEt})_{2}-\mathrm{Zn}-\mathrm{MLNC}$ and MTX-Zn-MLNC-MTX compared to either the drug solutions [MTX and $\operatorname{MTX}(\mathrm{OEt})_{2}$ ] or the blank-formulation (Phe-Zn-MLNC) (Figure 5).

Cell counting was performed using the Trypan blue dye exclusion test. Control 1 (DMEM) and the blank-formulations ( $\mathrm{LNC}^{+}$and Phe-Zn-MLNCN) showed similar cell viability $(p>0.05)$ (Figure 6), Phe-Zn-MLNC exhibited similar cell viability $(p>0.05)$ to $\mathrm{LNC}^{+}$, showing that both blank-formulations were not cytotoxic. On the other hand, Phe-Zn-MLNC-MTX $(\mathrm{OEt})_{2}, \operatorname{MTX}(\mathrm{OEt})_{2}-\mathrm{Zn}-\mathrm{MLNC}$ and MTX-Zn-MLNC-MTX significantly decreased $(p<0.05)$ cell viability when compared to Control 1 (DMEM) and to the blank-formulations ( $\mathrm{LNC}^{+}$and Phe-Zn-MLNC) (Figure 6). Furthermore, MTX $(\mathrm{OEt})_{2}$-Zn-MLNC and MTX-Zn-MLNC-MTX showed more significant reductions in cell viability $(p<0.05)$ than Phe-Zn-MLNC-MTX $(\mathrm{OEt})_{2}$.

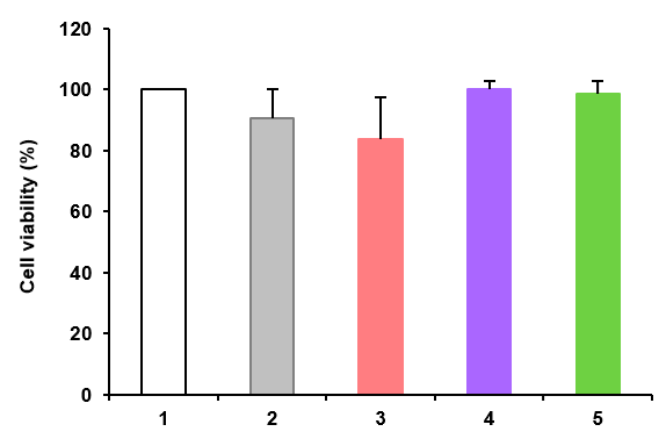

Figure 4. In vitro cytotoxicity in healthy immortalized human keratinocytes (HaCaT) investigated by MTT: (1) Control 1 (DMEM); (2) LNC $^{+}$; (3) Phe-Zn-MLNC-MTX(OEt) $)_{2}$; (4) MTX(OEt) $)_{2}$-Zn-MLNC; (5) MTX-Zn-MLNC-MTX. Data are presented as mean $\pm \mathrm{SD}(n=3)$.No statistical significant difference $(p>0.05)$ was observed between treatments (ANOVA, Tukey). 


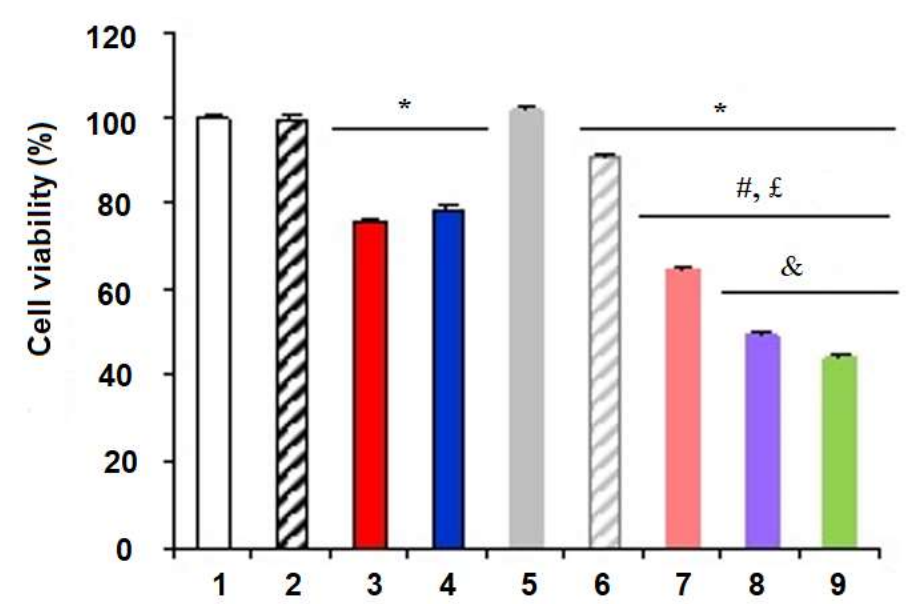

Figure 5. In vitro MCF-7 cells viability determined by MTT test, where (1) Control 1 (DMEM); (2) Control 2 (0.1\% DMSO); (3) MTX(OEt) 2 solution; (4) MTX solution; (5) $\mathrm{LNC}^{+}$(blank formulation); (6) Phe-Zn-MLNC (blank formulation); (7) Phe-Zn-MLNC-MTX(OEt) ${ }_{2}$; (8) MTX(OEt) $)_{2}-Z n-M L N C$; (9) MTX-Zn-MLNC-MTX. Data represent the mean \pm SD $(n=3),{ }^{*} p<0.05$ vs. Control (ANOVA, Tukey); $\# p<0.05$ vs. MTX solution (ANOVA, Tukey); $£ p<0.05$ vs. MTX(OEt) 2 solution (ANOVA, Tukey); \& $p<0.05$ vs. Phe-Zn-MLNC-MTX(OEt) ${ }_{2}$ (ANOVA, Tukey).

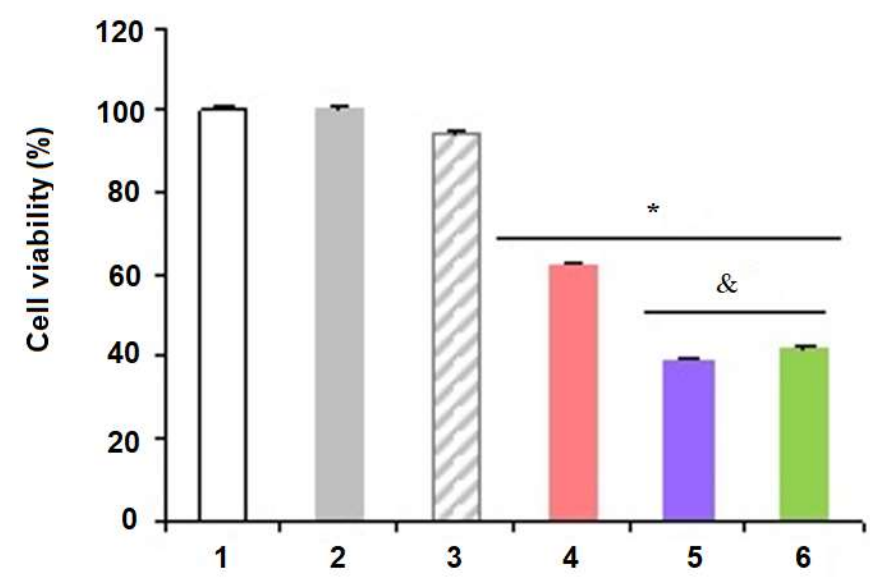

Figure 6. MCF-7 cells viability obtained by cell counting method, where (1) Control 1 (DMEM); (2) $\mathrm{LNC}^{+}$; (3) Phe-Zn-MLNC; (4) Phe-Zn-MLNC-MTX(OEt) ${ }_{2}$; (5) MTX(OEt) $)_{2}$-Zn-MLNC; (6) MTX-Zn-MLNC-MTX. Data represent mean $\pm \mathrm{SD}(n=3)$, * $p<0.05$ vs. Control (ANOVA, Tukey); $\& p<0.05$ vs. Phe-Zn-MLNC-MTX(OET) 2 (ANOVA, Tukey).

\section{Discussion}

The use of nanostructured materials has been very advantageous in cancer treatment when compared to conventional drug delivery systems [7]. Formulations based on nanotechnology reduce tumor size more effectively than non-encapsulated drugs $[8,10,11]$ due to cellular uptake of drugs. Furthermore, surface functionalization can provide drug to the targeted tissues [13] and reduce cytotoxicity, as demonstrated for mesoporous silica nanoparticles grafted with folic acid intended for two-photon imaging and photodynamic therapy [32].

Previously, we have developed an algorithm to correlate the mechanism of drug encapsulation and drug distribution in nanocapsules dispersed in water [33]. The lipophilicity of the drug, including its acid-base balance $(\log \mathrm{D})$, was the physico-chemical parameter with the most profound influence on drug distribution in LNC dispersed in water. In LNC, methotrexate is partially distributed in the PCL-wall of the lipid-core nanocapsules and mainly dissolved in the continuous phase when 
the interface consisted of PCL and polysorbate 80 [33], whereas methotrexate diethyl ester was distributed in the inner phase (the lipid-core) in the PCL and was partially dissolved in the outer phase (continuous phase). Moreover, the lipid-core nanocapsules were developed using biocompatible and biodegradable materials and can be considered promising building blocks for the development of surface-functionalized nanoparticles. Indeed, we have recently proposed an innovative strategy to bind ligands on the surface of polymeric nanocapsules $[23,24]$.

LNC has a lipid-core surrounded by PCL as a lipophilic architectural component, which was stabilized in water by polysorbate 80-micelles. When lecithin was added to the organic phase, the transmission electron microscopy analysis evidenced four layers of micellar structures coating LNC constituting a hydrophilic corona [34]. Furthermore, interfacial reactions on those lecithin-polysorbate 80-coated LNC, as substrate, produced $\mathrm{LNC}^{+}$and surface-functionalized-MLNC [23]. After adding a chitosan solution to the $\mathrm{LNC}^{-}$formulation, a lipid-core:PCL:chitosanconcentric architecture was obtained by confocal fluorescence microscopy using multi-color fluorescence-labeled MLNC [24].

Here, we have proposed the development of MLNC formulations to perform an in vitro study to evaluate the uptake and antiproliferative activity of methotrexate or its diethyl ester derivative. Phe-Zn-MLNC-MTX(OEt) ${ }_{2}$ and MTX-Zn-MLNC-MTX showed high incorporation efficiency (E\%) of methotrexate and its diethyl ester derivative, demonstrating that the chitosan coating, followed by the organometallic complex formation, was able to bind the soluble portion of the drug or its pro-drug to the reactant formulations $\mathrm{LNC}^{-}-\mathrm{MXT}$ and $\mathrm{LNC}^{-}-\mathrm{MTX}(\mathrm{OEt})_{2}$. MTX(OEt) $)_{2}-\mathrm{Zn}-\mathrm{MLNC}$ was also developed with high pro-drug incorporation efficiency. We did not oversaturate the colloidal phase since the $\mathrm{E} \%$ values were higher than $94 \%$. The physico-chemical properties of the formulations were adequate to their use in the in vitro biological evaluations.

Non-tumoral cells, such as HaCaT, have low expression of folate receptors [35]. Activated dihydrofolate reductase increases intracellular levels of tetrahydrofolate triggering the synthesis of purines and pyrimidines, precursors for the synthesis of DNA and RNA for cell replication. On the other hand, tumor cells, in general, such as MCF-7 cell line, grow faster and in a more disordered way and have greater need of nucleotides for DNA and RNA synthesis [36]. The nanocarriers functionalized with folic acid residues showed higher cellular uptake when compared to non-functionalized nanocarriers, such as folate-nanoparticles in cervical cancer cell line (HeLa) [37], folic acid-liposomes in mouth carcinoma line (KB) [38], folate-functionalized paclitaxel-loaded nanoparticles in cervical cancer (HeLa), glioma (C6) in fibroblast cell lines (NIH 3T3) [13] and multifunctional nanoparticles in human breast carcinoma line (MCF-7) and fibroblast cell line (NIH 3T3) [39]. As tumor cells have higher expression of folate receptors on their surface, they capture higher percentages of functionalized nanoparticles. Methotrexate encapsulated in BSA capped gold nanoparticles has effectively increased the drug antiproliferative activity when tested in MCF-7 cell culture [40]. Methotrexate has several adverse effects and its administration in a drug delivery system can be advantageous envisaging an active targeting of tumor tissues and cells. In this way, we hypothesized that MTX-Zn-MLNC-MTX and MTX $(\mathrm{OEt})_{2}-\mathrm{Zn}-\mathrm{MLNC}$, specific ligands for folate receptor and Phe-Zn-MLNC-MTX(OEt) ${ }_{2}$, that has phenylalanine on the surface, could exhibit diverse biological behaviors.

Initially, we have analyzed the influence of the drug localization in the nanocapsule on the cellular uptake using HaCaT and MCF-7 cultures. The HaCaT uptake study conducted with the multiwall lipid-core nanocapsule formulations showed that the nanocapsules were internalized in the cells compared to the control group. In addition, the surface functionalization did not affect the amount of fluorescence emission observed when the drug-containing nanoformulations [Phe-Zn-MLNC-MTX(OEt $)_{2}$, MTX-Zn-MLNC-MTX and MTX(OEt $\left.)_{2}-Z n-M L N C\right]$ were compared to the blank-nanoformulation $\left(\mathrm{LNC}^{+}\right)$. Conversely, in the MCF-7 uptake study, the surface functionalization had an impact on the nanocapsules internalization. Phe-Zn-MLNC-MTX(OEt) 2 , MTX-Zn-MLNC-MTX and MTX $(\mathrm{OEt})_{2}-\mathrm{Zn}-\mathrm{MLNC}$ showed higher cellular uptake than $\mathrm{LNC}^{+}$. Moreover, functionalized formulations containing MTX or $\mathrm{MTX}(\mathrm{OEt})_{2}$ on their surface [MTX-Zn-MLNC-MTX and $\left.\operatorname{MTX}(\mathrm{OEt})_{2}-\mathrm{Zn}-\mathrm{MLNC}\right]$ exhibited higher uptake by MCF-7 cell line than Phe-Zn-MLNC-MTX(OEt) ${ }_{2}$, 
in which $\operatorname{MTX}(\mathrm{OEt})_{2}$ was encapsulated within the nanocapsules and the surface was functionalized with phenylalanine. In MTX $(\mathrm{OEt})_{2}-\mathrm{Zn}-\mathrm{MLNC}$ and MTX-Zn-MLNC-MTX, methotrexate, a folic acid antagonist or its diester derivative, was functionalizing the surface and the molecules were then more exposed to interact with the folate receptor.

MCF-7 cellular uptake was visualized by confocal fluorescence microscopy using two fluorescent probes, 5AHBO-C8, a benzazole probe $(\log \mathrm{D}=5)$ incorporated into the lipid-core [24] and PCL-Rhob, a polymer-dye conjugate forming a blend with PCL [24]. It was possible to infer that the nanocapsules were internalized intact, since magenta secondary light color was observed in the merged image, as well as the blue spots, in the same image, suggesting the release of 5AHBO-C 8 from the nanocapsules within $24 \mathrm{~h}$ of incubation.

Additionally, even though HaCaT culture showed cell uptake after being incubated with the drug-containing nanoformulations, the cell viability was not affected, demonstrating the safety of the formulations for those non-tumoral cells. MTX(OEt $)_{2}-Z n-M L N C$ and MTX-Zn-MLNC-MTX, having MTX or MTX $(\mathrm{OEt})_{2}$ functionalizing the surface of the nanocapsules, showed higher antiproliferative activity than Phe-Zn-MLNC-MTX $(\mathrm{OEt})_{2}$, in which MTX $(\mathrm{OEt})_{2}$ was encapsulated into the lipid-core.

The multiwall lipid-core nanocapsule formulations containing MTX and MTX $(\mathrm{OEt})_{2}$ showed significantly higher antiproliferative activity in breast cancer cells, MCF-7, than the activity observed for the MTX and MTX $(\mathrm{OEt})_{2}$ solutions. Previously, it was demonstrated that glioma strains internalized drug-loaded LNC by endocytosis [41], while formulations containing a specific binder for folate receptor were internalized by endocytosis maybe mediated by the folate receptor [42]. In this way, we suggest that MTX $(\mathrm{OEt})_{2}$-Zn-MLNC and MTX-Zn-MLNC-MTX showed higher cell uptake and increased antiproliferative activity in MCF-7 probably due to the interaction with folate receptors present in those cells. Unequivocally, the formulations showed no cytotoxicity to non-tumoral cells (HaCaT) demonstrating selectivity for the cell lines with increased expression of folate receptors, such as MCF-7 (breast carcinoma cells).

\section{Materials and Methods}

\subsection{Materials}

Poly( $\varepsilon$-caprolactone) (PCL, $\left.\mathrm{M}_{\mathrm{W}}=14 \mathrm{~kg} \mathrm{~mol}^{-1}\right), \mathrm{Span}^{\circledR} 60$ (sorbitan monostearate, SM), low molecular weight chitosan (CS) (deacetylation degree: 75.6\%, viscosity: 20.000 cP), zinc acetate (\#383317) and phenylalanine (\#P17008) where purchased from Sigma-Aldrich Co. (Saint Louis, MO, USA); Medium chain triglyceride (MCT) and polysorbate 80 (P80) were acquired from Delaware (Porto Alegre, Brazil); Lipoid ${ }^{\circledR}$ S75 (LPS75) (soy phosphatidylcholine, 75\% pure) from Lipoid (Ludwigshafen am Rhein, Germany). Methotrexate was acquired from Pharma Nostra (Campinas, Brazil) and dithizone from Merck (Darmstadt, Germany). DMEM (Dulbecco's modified Eagle's medium), penicillin/streptomycin, trypsin/EDTA and MTT (3-(4,5-Dimethylthiazol-2-yl)-2,5-diphenyltetrazolium bromide) were supplied by Sigma-Aldrich Co. Fetal Bovine Serum (FBS) was purchased from Gibco (Langley, OK, USA). The fluorescent dye-conjugates 2-(5'-N-octylamino-2'-hydroxyphenyl)benzoxazole, 5AHBO-C8 and rhodamine B-poly( $\varepsilon$-caprolactone) conjugate, PCL-RhoB, were prepared and characterized as previously described [24]. All other reagents and solvents used were analytical or pharmaceutical grade and were used as received.

\subsection{Methods}

\subsubsection{Preparation of MLNC Containing Methotrexate and Its Ester}

\section{Methotrexate Ethyl Ester}

Initially, the synthesis of methotrexate ethyl ester [MTX $\left.(\mathrm{OEt})_{2}\right]$ was performed according to the methodology previously described [33]. Briefly, methotrexate (1 mmol, $455 \mathrm{mg})$ was added in ethanol 
$(30 \mathrm{~mL})$ under magnetic stirring at room temperature. Afterwards, 4-dimethylaminopyridine (DMAP; $0.4 \mathrm{mmol}, 6 \mathrm{mg}$ ) and dicyclohexylcarbodiimide (DCC; $2 \mathrm{mmol}, 416 \mathrm{mg}$ ) were added. The product was purified by column chromatography using silica gel 60 (70-230 mesh) as stationary phase and chloroform:methanol $(99: 1 \mathrm{v} / \mathrm{v})$, using traces of ammonium hydroxide, as eluent.

Solutions of Chitosan, Zinc Acetate, Phenylalanine and Methotrexate Ethyl Ester

Aqueous solution of chitosan $(1 \%, w / v)$ was prepared by dissolving, in a volumetric flask $(10 \mathrm{~mL})$, $101 \pm 3 \mathrm{mg}$ of chitosan in $1 \%$ acetic acid $(v / v)$ aqueous solution. Aqueous solution of zinc acetate was obtained by adding $28 \pm 1 \mathrm{mg}$ of zinc acetate in a volumetric flask and completing with water to a volume of $10 \mathrm{~mL}$. For phenylalanine solution, $75 \pm 2 \mathrm{mg}$ of amino acid was weighed and the volume was completed with water to $10 \mathrm{~mL}$. After complete dissolution, at room temperature, the solutions were filtered using a $0.45 \mathrm{mM}$ membrane (Millipore $\left.{ }^{\circledR}\right)$. The $\mathrm{MTX}(\mathrm{OEt})_{2}$ solution was prepared by dissolving $11.3 \pm 0.8 \mathrm{mg}$ of the drug in ultrapure water-ethanol mixture $(1: 1, v / v)$ in a volumetric flask $(10 \mathrm{~mL})$.

\section{Preparation of MTX(OEt $)_{2}$-Zn-MLNC Formulation}

The first step of synthesis was to assemble the materials to generate lipid-core nanocapsules stabilized with polysorbate 80 -lecithin. $\mathrm{LNC}^{-}$was prepared by adding an ethanol solution of soybean lecithin in a PCL, sorbitan monostearate (SM) and medium chain triglycerides (MCT) acetone solution, at $40^{\circ} \mathrm{C}$. This organic solution was injected in an aqueous phase containing polysorbate 80 (P80) at $40^{\circ} \mathrm{C}$. The turbid solution was stirred for $10 \mathrm{~min}$. The organic solvents were then eliminated and the formulation concentrated to $10 \mathrm{~mL}$ in a rotary evaporator (Büchi, Flawil, Switzerland) under reduced pressure at $40{ }^{\circ} \mathrm{C}$. Then, $\mathrm{LNC}^{+}$was produced by adding $1 \mathrm{~mL}$ of aqueous solution of chitosan $(1 \%)$ to $9 \mathrm{~mL}$ of $\mathrm{LNC}^{-}$formulation. The reaction was maintained under stirring for $2 \mathrm{~h}$. Then, $\mathrm{LNC}^{+}(9 \mathrm{~mL})$ was added to $1 \mathrm{~mL}$ of zinc acetate solution and ( $1 \mathrm{~min}$ after) of $1 \mathrm{~mL}$ of MTX $(\mathrm{OEt})_{2}$ hydroalcoholic solution. This reaction was maintained under stirring for $2 \mathrm{~h}$.

Table 3 shows the comparative quali-quantitative composition of formulations. The final theoretical concentration of methotrexate diethyl ester in the formulation was $2.2 \mathrm{mmol} \cdot \mathrm{L}^{-1}$.

Table 3. Quali-quantitative composition of $\mathrm{LNC}^{+}$, Phe-Zn-MLNC, Phe-Zn-MLNC-MTX(OEt) ${ }_{2}$, $\operatorname{MTX}(\mathrm{OEt})_{2}-\mathrm{Zn}-\mathrm{MLNC}$ and MTX-Zn-MLNC-MTX formulations prepared in triplicate batches.

\begin{tabular}{|c|c|c|c|c|c|}
\hline & $\mathrm{LNC}^{+}$ & Phe-Zn-MLNC & $\operatorname{MTX}(\mathrm{OEt})_{2}-\mathrm{Zn}-\mathrm{MLNC}$ & MTX-Zn-MLNC-MTX & Phe-Zn-MLNC-MTX $(\mathrm{OEt})_{2}$ \\
\hline PCL (mg) & $102 \pm 1$ & $101 \pm 2$ & $100 \pm 2$ & $100 \pm 1$ & $99 \pm 2$ \\
\hline $\mathrm{SM}(\mathrm{mg})$ & $40 \pm 2$ & $42 \pm 1$ & $40 \pm 3$ & $39 \pm 1$ & $41 \pm 2$ \\
\hline MCT (mL) & 0.12 & 0.12 & 0.12 & 0.12 & 0.12 \\
\hline Acetone (mL) & 25 & 25 & 25 & 25 & 25 \\
\hline LPS75 (mg) & $59 \pm 1$ & $60 \pm 2$ & $60 \pm 3$ & $61 \pm 1$ & $62 \pm 1$ \\
\hline Ethanol (mL) & 4 & 4 & 4 & 4 & 4 \\
\hline P80 (mg) & $80 \pm 2$ & $79 \pm 3$ & $80 \pm 2$ & $80 \pm 2$ & $78 \pm 1$ \\
\hline Water $(\mathrm{mL})$ & 50 & 50 & 50 & 51 & 50 \\
\hline Chitosan (mg) & 1 & 1 & 1 & 1 & 1 \\
\hline Zinc acetate (mg) & - & $2.8^{*}$ & $2.8^{*}$ & $2.8^{*}$ & $2.8^{*}$ \\
\hline Phenylalanine (mg) & - & 8 & - & - & 8 \\
\hline $\operatorname{MTX}(\mathrm{mg})$ & - & - & - & $1.03 \pm 0.6$ & - \\
\hline $\operatorname{MTX}(\mathrm{OEt})_{2}(\mathrm{mg})$ & - & - & $1.13 \pm 0.8$ & - & $1.12 \pm 0.3$ \\
\hline Final volume (mL) & 11 & 11 & 11 & 11 & 11 \\
\hline
\end{tabular}

Note: Data are expressed as mean \pm standard deviation. ${ }^{*}$ Equivalent $1 \mathrm{mg}$ zinc-II. Abbreviations: LNC ${ }^{+}$, chitosan-coated lipid-core nanocapsules; Phe-Zn-MLNC, multiwall lipid-core nanocapsules functionalized with phenylalanine; Phe-Zn-MLNC-MTX $(\mathrm{OEt})_{2}$, multiwall lipid-core nanocapsules functionalized with phenylalanine with methotrexate ester encapsulated; $\mathrm{MTX}(\mathrm{OEt})_{2}-\mathrm{Zn}-\mathrm{MLNC}$, multiwall lipid-core nanocapsules functionalized with methotrexate ester; MTX-Zn-MLNC-MTX, multiwall lipid-core nanocapsules functionalized with methotrexate; PCL, poly(E-caprolactone); SM, sorbitan monostearate; MCT, medium chain triglycerides; LPS75, Soybean Lecithin $75 \%$, P80, polysorbate 80; Zn, zinc; MTX, methotrexate; MTX $(\mathrm{OEt})_{2}$, methotrexate ester.

\section{Preparation of MTX-Zn-MLNC-MTX Formulation}

A solution of soybean lecithin $75 \%$ in ethanol was added to a colorless transparent acetone solution of PCL, SM, MCT and methotrexate under magnetic stirring at $40^{\circ} \mathrm{C}$. The organic solution 
was continuously injected into an aqueous solution containing P80 under moderate magnetic stirring at $40{ }^{\circ} \mathrm{C}$ (Table 3). The organic solvent was eliminated and part of water removed under reduced pressure at $40{ }^{\circ} \mathrm{C}$, concentrating the formulation to approximately $10 \mathrm{~mL}$. The final volume was adjusted using ultrapure water to $10 \mathrm{~mL}$ in a volumetric flask to obtain $\mathrm{LNC}^{-}-\mathrm{MTX}$. Afterwards, $1 \mathrm{~mL}$ of $1 \%$ chitosan aqueous solution was slowly added under moderate stirring at $25{ }^{\circ} \mathrm{C}$ to $9 \mathrm{~mL}$ of $\mathrm{LNC}^{-}-\mathrm{MTX}$ to obtain $\mathrm{LNC}^{+}-\mathrm{MTX}$. The reaction was maintained under stirring for $2 \mathrm{~h}$. The final step to obtain the functionalized formulations consisted of adding $1 \mathrm{~mL}$ of zinc acetate solution and (1 min after) $1 \mathrm{~mL}$ of water (to have similar concentrations among formulations) to $9 \mathrm{~mL}$ of $\mathrm{LNC}^{+}$-MTX under moderate stirring at $25^{\circ} \mathrm{C}$. The reaction was maintained under stirring for $2 \mathrm{~h}$. The final theoretical concentration of methotrexate in the formulation was $2.2 \mathrm{mmol} \cdot \mathrm{L}^{-1}$.

Preparation of the Phe-Zn-MLNC-MTX $(\mathrm{OEt})_{2}$ Formulation

$\mathrm{LNC}^{-}-\mathrm{MTX}(\mathrm{OEt})_{2}$ was prepared by adding an ethanol solution of soybean lecithin to a transparent and colorless organic phase containing PCL, SM, MCT and methotrexate diethyl ester. Afterwards, the transparent and colorless mixture was continuously injected into an aqueous solution containing polysorbate 80 (P80) under moderate magnetic stirring at $40{ }^{\circ} \mathrm{C}$ (Table 3). The organic solvents and part of water were removed under reduced pressure to concentrate the formulation until approximately $10 \mathrm{~mL}$. The final volume was adjusted using ultrapure water to $10 \mathrm{~mL}$ in a volumetric flask. Following, $9 \mathrm{~mL}$ of $\mathrm{LNC}^{-}-\mathrm{MTX}(\mathrm{OEt})_{2}$ was added to $1 \mathrm{~mL}$ of $1 \%$ chitosan aqueous solution, which was slowly added under moderate stirring at $25{ }^{\circ} \mathrm{C}$. The reaction was maintained under stirring for $2 \mathrm{~h}$. The final step to obtain the Phe-Zn-MLNC-MTX $(\mathrm{OEt})_{2}$ formulation was performed by adding $1 \mathrm{~mL}$ zinc acetate solution and $1 \mathrm{~mL}$ of phenylalanine solution to $9 \mathrm{~mL}$ of the $\mathrm{LNC}^{+}-\mathrm{MTX}(\mathrm{OEt})_{2}$ turbid solution under moderate stirring at $25{ }^{\circ} \mathrm{C}$. The reaction was maintained under stirring for $2 \mathrm{~h}$. The final theoretical concentration of methotrexate diethyl ester in the formulation was $2.2 \mathrm{mmol} \cdot \mathrm{L}^{-1}$. Blank formulations $\left(\mathrm{LNC}^{+}\right.$and Phe-Zn-MLNC) were also prepared (Table 3).

Synthesis of MLNC Formulations Containing Fluorescent Probes

The fluorescent-labeled formulations were prepared with $2.2 \mathrm{mmol} \cdot \mathrm{L}^{-1}$ of MTX or MTX $(\mathrm{OEt})_{2}$ according to the procedure described above, substituting $0.5 \mathrm{mg}$ of PCL by $0.5 \mathrm{mg}$ of rhodamine B-poly ( $\varepsilon$-caprolactone) conjugate (PCL-RhoB) in the formulations. The fluorescent-labeled formulations were named f-MTX(OEt) $)_{2}$ Zn-MLNC, f-MTX-Zn-MLNC-MTX and f-Phe-Zn-MLNC-MTX(OEt) . Fluorescent-labeled-chitosan-coated lipid-core nanocapsule formulation $\left(\mathbf{f}-\mathrm{LNC}^{+}\right)$was prepared as control in cellular uptake studies.

Double-fluorescent-labeled formulation was prepared with $2.2 \mathrm{mmol} \cdot \mathrm{L}^{-1}$ of MTX (ff-MTX-Zn-MLNC-MTX), according to the procedure previously described for multifluorescent-labeled multi-wall lipid-core nanocapsules [24]. Briefly, an acetone solution (25 mL) containing PCL (99.5 mg), PCL-RhoB (0.5 mg), 5AHBO-C8 (1.0 mg), sorbitan monostearate (40 mg) and MCT (120 mg) was added to a soybean lecithin (60 mg) ethanol solution (4 mL). The organic solution was injected into the aqueous solution containing polysorbate 80 (80 mg) under moderate magnetic stirring at $40^{\circ} \mathrm{C}$. The organic solvents and excessive water were removed under reduced pressure at $40{ }^{\circ} \mathrm{C}$ to approximately $9 \mathrm{~mL}$ using a rotary evaporator. The final volume was adjusted to $10 \mathrm{~mL}$ in a volumetric flask.

\subsubsection{Physicochemical Characterization of Formulations}

Laser Diffraction Analysis

Particle size distribution was carried out by laser diffraction (LD) method using a Mastersizer ${ }^{\circledR}$ 2000 (Malvern Instruments Ltd., Malvern, UK) in the size range 0.02 to $2000 \mu \mathrm{m}$. Each sample (without any treatment) was inserted into the dispersion unit (Hydro 2000SM-AWM2002, Malvern, UK) containing approximately 100 to $200 \mathrm{~mL}$ of distilled water with sufficient amount to achieve 
obscuration between $1 \%$ and $8 \%$. The Malvern software was used to determine the specific area, the mean diameter and polydispersity. Specific surface area was determined considering the density of $1 \mathrm{~g} \mathrm{~m} \cdot \mathrm{L}^{-1}$ for all formulations. The diameter distribution curve (expressed by the volume of particles) was used to calculate the equivalent spherical diameter, i.e. volume-weighted mean diameter $(\mathrm{D}[4,3])$ and polydispersity (SPAN), using Equations (1) and (2), respectively.

$$
\begin{gathered}
\mathrm{D}[4,3]=\frac{\sum_{i}^{n} d_{i v_{i}}^{4}}{\sum_{i}^{n} d_{i v_{i}}^{3}} \\
\mathrm{SPAN}=\frac{\mathrm{D}_{0.9}-\mathrm{D}_{0.1}}{\mathrm{D}_{0.5}} \times 100
\end{gathered}
$$

where $i$ is an index of the population and $d_{i}$ is the particle diameter of the population $i, \mathrm{D}_{0.1}, \mathrm{D}_{0.5}$ and $\mathrm{D}_{0.9}$ are the diameters at percentiles 10,50 and 90 of the particles, respectively, under the cumulative size distribution curve based on the volume of particles.

\section{Dynamic Light Scattering}

The hydrodynamic diameter calculated by the method of cumulants (Dz-ave) and the polydispersity index (PDI) of the nanoparticles were analyzed by dynamic light scattering (DLS) using a Zetasizer Nano®ZS (Malvern Instruments Ltd., Malvern, UK). To avoid any sample selection, each formulation was diluted (250-folds), without any treatment, in pre-filtered (0.45 $\mu$ m, Millipore, Bedford, MA, USA) ultrapure water (Milli- $\mathrm{Q}^{\circledR}$ water). Diffusion coefficient (DC) was calculated using Stokes-Einstein equation by PCS.

\section{Nanoparticle Tracking Analysis}

Nanoparticle tracking analysis was performed with a NanoSight LM10 (LM10 \& NanoSight NTA 2.0 Analytical Software, NanoSight Ltd., Wiltshire, UK). Brownian motion of nanoparticles [43] and the scattering of the incident radiation $(635 \mathrm{~nm})$ were captured by a CCD camera to produce a video. The analysis of each video clip by NTA software 2.0 Build 127 (NanoSight) allowed the measurement of number density of particles and their size distributions. Prior to the analysis, the formulations were diluted $5000 \times$ in pre-filtered $\left(0.45 \mu \mathrm{m}\right.$, Millipore) ultrapure water (MilliQ $\left.{ }^{\circledR}\right)$. After dilution, the samples were injected into the sample chamber and analyzed for $60 \mathrm{~s}$ at room temperature. Gain and shutter were adjusted manually.

\section{Zeta Potential}

Zeta potential was determined by means of laser Doppler velocimetry and electrophoretic mobility, utilizing a Malvern Zetasizer ${ }^{\circledR}$ Nano ZS (Malvern Instruments Ltd., Malvern, UK) at $20{ }^{\circ} \mathrm{C}$ after dilution of sample (250-folds) in pre-filtered $\left(0.45 \mu \mathrm{m}\right.$, Millipore) $10 \mathrm{mmol} \cdot \mathrm{L}^{-1} \mathrm{NaCl}$ aqueous solution. The results are presented as the average of three replicate analyses.

Potentiometry

The $\mathrm{pH}$ values of the formulations were measured with a potentiometer (Denver Instrument, Model UB-10, Bohemia, NY, USA) previously calibrated and equipped with an Ag/ AgCl reference electrode (Analion V620, Ribeirão Preto, Brazil). Measurements were performed without dilution.

\section{Zinc Ion Quantification}

Dialysis of formulations was used to isolate zinc-II soluble in water, as previously described [24]. Formulations were placed in cellulose membranes (10 kDa, Sigma-Aldrich, Saint Louis, MO, USA) and dialyzed against ultrapure water, as medium. Experiments were conducted for $6 \mathrm{~h}$, with moderate agitation at $25^{\circ} \mathrm{C}$. Samples $(n=3)$ were collected every $2 \mathrm{~h}$. Zinc assay was performed using a UV-Vis 
spectrophotometer (CE UV-1800 PC, PRO-ANÁLISE, Porto Alegre, Brazil) at $\lambda=514 \mathrm{~nm}$, using dithizone $\left(13 \mathrm{ng} \cdot \mathrm{mL}^{-1}\right)$ as a chromogenic agent. Zinc ion concentrations were calculated using Equation (3).

$$
C_{\text {Zinc-II }}=\frac{[T-(x+y+z)]}{T} \times 100
$$

where $C_{\text {Zinc-II }}$ is the percentage (\%) of $\mathrm{Zn}^{2+}$ coordinated nanocapsules $(w / v), T$ is the total concentration of $\mathrm{Zn}^{2+}$ added to the formulation and $x, y$ and $z$ are the concentrations of zinc-II in each solution fraction analyzed. To quantify the samples, the method was validated again, considering linearity, precision, repeatability and accuracy.

\section{MTX and MTX-Ester Quantifications}

Drugs were quantified using an HPLC instrument (Perkin Elmer S-200, Shelton, WA, USA) equipped with a S-200 autosampler and an S-200 UV-VIS detector. The stationary phase consisted of a RP Waters Spherisorb ${ }^{\circledR} \mathrm{C}_{18}$ analytical column $(150 \mathrm{~mm} \times 4 \mathrm{~mm}, 4 \mu \mathrm{m}$ particle size). The formulations containing MTX were extracted with acetonitrile and tetrahydrofuran (THF) 4:6 (v/v). Meanwhile, formulations containing $\mathrm{MTX}(\mathrm{OEt})_{2}$ were extracted with methanol. The dilutions were filtrated prior to analysis (Millipore, $0.45 \mu \mathrm{m}$ ) to separate the dispersed components from the extracted drugs.

Quantifications of MTX and MTX $(\mathrm{OEt})_{2}$ were performed according to methodologies previously described $[33,44]$. The injection volume was $20 \mu \mathrm{L}$ for both analytes. The drugs were detected at $303 \mathrm{~nm}$. For MTX, the mobile phase consisted of metanol:water:tetrahydrofuran (20:70:10 $\mathrm{v} / \mathrm{v} / \mathrm{v})$, apparent $\mathrm{pH}$ of $6.0 \pm 0.5$ adjusted with $10 \%(v / v)$ acetic acid solution. Flow rate was fixed in $0.8 \mathrm{~mL} \mathrm{~min}{ }^{-1}$. For MTX $(\mathrm{OEt})_{2}$, the mobile phase was methanol:water $(80: 20 v / v)$, with apparent $\mathrm{pH}$ of $4.0 \pm 0.5$ adjusted with $10 \%(v / v)$ acetic acid solution and flow rate of $1.0 \mathrm{~mL} \mathrm{~min}^{-1}$. Both methods showed correlation coefficients higher than 0.99 in the concentration range of $1-50 \mu \mathrm{g} \cdot \mathrm{mL}^{-1}$ and variation coefficients lower than $5 \%$ for repeatability and intermediate precision.

To determine the encapsulation (or functionalization) efficiency (EE), $0.3 \mathrm{~mL}$ of the formulation was poured into an Ultra-free unit (Microcon, cut-off $10 \mathrm{kDa}$, Millipore ${ }^{\circledR}$, Burlington, MA, USA) for ultrafiltration-centrifugation at $1844 \times g(\mathrm{RCF})$ for $5 \mathrm{~min}$ in a centrifugal filter device (Sigma ${ }^{\circledR} 1-14$, Osterode am Harz, Germany). The encapsulation (functionalization) efficiency (EE\%) was calculated using Equation (4).

$$
E E \%=\frac{C_{t}-C_{f}}{C_{t}} \times 100
$$

where $C_{t}$ is the total drug concentration in the formulation and $C_{f}$ is the drug concentration of the ultrafiltrate.

\subsubsection{In Vitro Biological Evaluations}

\section{Cell Cultures}

Immortalized Human Keratinocytes (HaCaT) cell line was kindly provided by Luisa L. Villa PhD (ICESP, School of Medicine, University of São Paulo, São Paulo, Brazil) and Silvya S. Maria-Engler PhD (Faculty of Pharmaceutical Sciences, University of São Paulo, São Paulo, Brazil). Human breast cancer cell line (MCF-7) was obtained from American Type Collection Culture (ATCC, Rockville, MD, USA). Both cell lines were cultivated in DMEM (Dulbecco's Modified Eagle Medium) supplemented with $10 \%$ of fetal bovine serum (FBS) at $37{ }^{\circ} \mathrm{C}$ and $5 \% \mathrm{CO}_{2}$.

\section{Cellular Uptake Studies}

Cell suspensions were seeded at a density of $6.0 \times 10^{3}$ cells per well in 24-well culture plates. After reaching semi-confluence, HaCaT and MCF-7 cells were incubated with f-LNC ${ }^{+}$, f-MTX $(\mathrm{OEt})_{2}-\mathrm{Zn}$-MLNC, f-MTX-Zn-MLNC-MTX and f-Phe-Zn-MLNC-MTX $(\mathrm{OEt})_{2}$. The drugs were used at $0.17 \mathrm{mmol} \cdot \mathrm{L}^{-1}$ and the cells incubated for $24 \mathrm{~h}$ at $37^{\circ} \mathrm{C}$. Afterwards, the media were removed 
and the wells were washed three times with phosphate-buffered saline (PBS), harvested and analyzed using a flow cytometer (BD FACSVerse) to determine the fluorescence intensity emitted by the polymer-dye conjugate (PCL-RhoB). Relative uptake for each formulation was calculated using the Equation (5), considering $\mathbf{f}-\mathrm{LNC}^{+}$as control $\left(F I_{i}=\right.$ fluorescence intensity of formulation and $\mathrm{FI}_{f-L N C}{ }^{+}=$fluorescence intensity of $\mathbf{f}-\mathrm{LNC}^{+}$):

$$
\text { relative cellular uptake }=\frac{F I_{i}}{F I_{f-L N C^{+}}}
$$

Qualitative MCF-7 cells uptake was determined by confocal microscopy. Cells were seeded over round glass coverslips placed into 24 -well culture plates. After $24 \mathrm{~h}$ of incubation at $37^{\circ} \mathrm{C}$ with $\mathbf{f}-\mathrm{LNC}^{+}$, f-MTX $(\mathrm{OEt})_{2}$-Zn-MLNC, f-MTX-Zn-MLNC-MTX and f-Phe-Zn-MLNC-MTX(OEt) $2\left(\right.$ at $0.17 \mathrm{mmol} \cdot \mathrm{L}^{-1}$ of each drug), the media were removed, the wells were washed three times with PBS and the coverslips were transferred to the microscope slides. The slides were observed using an Olympus Laser Confocal Microscope (fv1000, Olympus, Tokyo, Japan). PCL-RhoB (red fluorescence) and 5AHBO-C8 (blue fluorescence) were excited using a $559 \mathrm{~nm}$ laser and a $405 \mathrm{~nm}$ laser, respectively.

\section{In Vitro Antiproliferative Activity}

Cells were cultivated in 96-well plates and after reaching a semi-confluency, they were treated with aqueous solution of $\mathrm{MTX}(\mathrm{OEt})_{2}$ containing $0.1 \%$ of $\mathrm{DMSO} ; \mathrm{LNC}^{+}$; Phe-Zn-MLNC; Phe-Zn-MLNC-MTX(OEt) $)_{2}$; MTX(OEt) $)_{2}-Z n-M L N C$ and MTX-Zn-MLNC-MTX, using drug concentrations at $2.74 \mathrm{mmol} \cdot \mathrm{L}^{-1}$ and incubated at $37^{\circ} \mathrm{C}$. DMEM supplemented with $10 \%$ of FBS was used as control. Cells were also treated with $0.1 \%$ of DMSO to determine their toxicity with the same conditions used in the drug derivative solution.

Negative controls consisted of applying the culture medium (DMEM) or 0.1\% DMSO aqueous solution, which was used as solvent for the pure drugs [MTX and MTX $(\mathrm{OEt})_{2}$ ]. Blank formulations $\left(\mathrm{LNC}^{+}\right.$and Phe-Zn-MLNC) were used for comparative purposes. Furthermore, the test groups consisted of MTX and MTX $(\mathrm{OEt})_{2}$ solutions and the nanoformulations [Phe-Zn-MLNC-MTX $(\mathrm{OEt})_{2}$, MTX(OEt) $)_{2}$-Zn-MLNC and MTX-Zn-MLNC-MTX].

In vitro antiproliferative activity was evaluated using MTT assay (3-(4,5-dimethylthiazol-2-yl)2,5-diphenyltetrazolium bromide). After $24 \mathrm{~h}$ of incubation, media containing the nanoformulations were replaced by a $0.5 \mathrm{mg} \cdot \mathrm{mL}^{-1} \mathrm{MTT}$ solution. Plates were further incubated at $37{ }^{\circ} \mathrm{C}$ for $3 \mathrm{~h}$. Formazan crystals, formed by tetrazolium cleaved in active mitochondria, were dissolved using DMSO and quantified at $570 \mathrm{~nm}$ and $630 \mathrm{~nm}$ in a microplate reader (Spectramax M2e, SoftMax ${ }^{\circledR}$ Pro Software Interface 5.4.1, Sunnyvale, CA, USA). The results were expressed as percentage compared to controls. Cell viability was considered to be $100 \%$.

Trypan blue dye exclusion test was used to confirm cell viability. After $24 \mathrm{~h}$ of treatment application, the medium (DMEM) was removed from the wells and cells were washed with PBS. Trypsin $/ 0.25 \%$ EDTA was added to detach cells from the wells. Later on, DMEM/10\% FBS was added and cell suspensions were diluted with trypan blue $(1: 1, v / v)$ to selectively stain dead cells. The viable cells (trypan blue negative) were counted with a Neubauer chamber under an optical microscope (Olympus, CX21 model, Tokyo, Japan). Results were expressed as percentage compared to control (DMEM/10\% FBS), which represents 100\% cell viability.

\subsubsection{Statistical Analysis}

Data were expressed as mean \pm standard deviation. Results were analyzed by ANOVA followed by Tukey post-test. The statistical analysis was performed using GraphPad Prism 5.0 software (GraphPad Software Inc., La Jolla, CA, USA). The significance level of was set at 5\% $(p \leq 0.05)$. 


\section{Conclusions}

In this study, we have developed surface-functionalized multi-wall nanocapsules using an innovative strategy based on the use of soft nanocapsules as building blocks. Lipid-core nanocapsules prepared via self-assembly were coated with polysorbate 80-lecithin and reacted with chitosan, zinc acetate and methotrexate, methotrexate diethyl ester or phenylalanine generating three formulations containing different drug binding to the nanocapsules: Phe-Zn-MLNC-MTX $(\mathrm{OEt})_{2}$, MTX-Zn-MLNC-MTX and MTX(OEt) ${ }_{2}-Z n-M L N C$. All formulations were obtained as single nanoscopic populations with no additional purification steps. All formulations showed cell uptake after incubation in immortalized non-tumoral cells (HaCaT) or in tumor cells (MCF-7). However, in MCF-7, the internalization of the nanocapsules was higher for the formulations presenting specific ligands for folate receptor on the surface (MTX(OEt) 2 -Zn-MLNC and MTX-Zn-MLNC-MTX), while in HaCaT, they were similar disregarding the surface of the nanocapsules. No antiproliferative activity was observed in HaCaT culture after incubation with Phe-Zn-MLNC-MTX(OEt) ${ }_{2}$, MTX-Zn-MLNC-MTX and $\mathrm{MTX}(\mathrm{OEt})_{2}-\mathrm{Zn}-\mathrm{MLNC}$, whereas those formulations showed antiproliferative activity against MCF-7 cells. Finally, MTX(OEt) $)_{2}$ Zn-MLNC and MTX-Zn-MLNC-MTX which have specific ligands for the folate receptor on the nanocapsule surface, showed enhanced and selective antiproliferative activity to human breast cancer cells (MCF-7). Methotrexate-functionalized-nanocapsules are promising devices for further in vivo preclinical evaluations.

Supplementary Materials: The following are available online at http:/ / www.mdpi.com/2079-4991/8/1/24/s1, Figure S1: Confocal laser photomicrographies of MCF-7 cells: column 1 corresponds to images recorded using differential interface contrast, column 2 corresponds to images recorded by using red dye fluorescence channel and laser excitation at $559 \mathrm{~nm}$ and column 3 corresponds to the merged images of columns 1 and 2; (a) f-LNC f $^{+}$ (b) f-Phe-MLNC-Zn-MTX $(\mathrm{OEt})_{2}$; (c) f-MTX $(\mathrm{OEt})_{2}$-MLNC-Zn and (d) f-MTX-MLNC-Zn-MTX, Figure S2: Confocal laser photomicrographies of MCF-7 cells after $24 \mathrm{~h}$ of incubation with ff-MTX-MLNC-Zn-MTX: (a) image obtained using differential interface contrast; (b) image obtained after excitation at $405 \mathrm{~nm}$ using blue fluorescence channel; (c) image obtained after excitation at $559 \mathrm{~nm}$ using red fluorescence channel; and (d) merged image using 3 channels (grey: cells, blue: emission from 5AHBO-C8 and red: emission from PCL-RhoB).

Acknowledgments: We are grateful to Felipe Coelho, Leandra F. Campos and Fabiano S. Rodembusch for the synthesis of 5AHBO-C8 fluorescent dye.

Author Contributions: The investigation was planned by A.R.P. and S.S.G. Rhodamine B-poly( $\varepsilon$-caprolactone) conjugate (PCL-RhoB) was synthesized and characterized by W.A.P. with guidance from A.R.P.. The development and characterization of the nanocapsules were done by C.P.d.O., W.A.P. and S.L.B. with guidance from A.R.P. and S.S.G. Cell culture experiments were performed by C.P.d.O., A.B. and A.C.A. with guidance from A.B. Data processing and the writing of this manuscript were done by C.P.d.O., A.R.P. and S.S.G. with input from all co-authors. All authors read and approved the final manuscript.

Conflicts of Interest: The authors declare no conflict of interest.

\section{References}

1. Bernardi, A.; Frozza, R.L.; Meneghetti, A.; Hoppe, J.B.; Battastini, A.M.; Pohlmann, A.R.; Guterres, S.S.; Salbego, C.G. Indomethacin-loaded lipid-core nanocapsules reduce the damage triggered by A $\beta 1-42$ in Alzheimer's disease models. Int. J. Nanomed. 2012, 7, 4927-4942. [CrossRef] [PubMed]

2. Vyas, D.; Castro, P.; Saadeh, Y.; Vyas, A. The role of Nanotechnology in gastrointestinal cancer. J. Biomed. Nanotechnol. 2014, 10, 3204-3218. [CrossRef] [PubMed]

3. Chiang, C.-H.; Hu, S.-H.; Liao, B.-J.; Chang, Y.-C.; Chen, S.-Y. Enhancement of cancer therapy efficacy by trastuzumab-conjugated and $\mathrm{pH}$-sensitive nanocapsules with the simultaneous encapsulation of hydrophilic and hydrophobic compounds. Nanomedicine 2014, 10, 99-107. [CrossRef] [PubMed]

4. Hoppe, J.B.; Coradini, K.; Frozza, R.L.; Oliveira, C.M.; Meneghetti, A.B.; Bernardi, A.; Pires, E.S.; Beck, R.C.R.; Salbego, C.G. Free and nanoencapsulated curcumin suppress $\beta$-amyloid-induced cognitive impairments in rats: Involvement of BDNF and Akt/GSK-3ß signaling pathway. Neurobiol. Learn. Mem. 2013, 106, 134-144. [CrossRef] [PubMed] 
5. Jaques, J.A.S.; Doleski, P.H.; Castilhos, L.G.; da Rosa, M.M.; Souza, V.C.; Carvalho, F.B.; Marisco, P.; Thorstenberg, M.L.; Rezer, J.F.; Ruchel, J.B.; et al. Free and nanoencapsulated curcumin prevents cigarette smoke-induced cognitive impairment and redox imbalance. Neurobiol. Learn. Mem. 2013, 100, 98-107. [CrossRef] [PubMed]

6. Li, J.; Hu, X.L.; Liu, M.; Hou, J.; Xie, Z.G.; Huang, Y.B.; Jing, X.B. Complex of cisplatin with biocompatible poly(ethylene glycol) with pendant carboxyl groups for the effective treatment of liver cancer. J. Appl. Polym. Sci. 2014, 131, 1-9. [CrossRef]

7. Cheng, F.; Cai, W. Tumor Vasculature Targeting: A Generally Applicable Approach for Functionalized Nanomaterials. Small 2014, 10, 1887-1893. [CrossRef] [PubMed]

8. Guo, J.; Gao, X.; Su, L.; Xia, H.; Gu, G.; Pang, Z.; Jiang, X.; Yao, L.; Chen, J.; Chen, H. Aptamer-functionalized PEG-PLGA nanoparticles for enhanced anti-glioma drug delivery. Biomaterials 2011, 32, 8010-8020. [CrossRef] [PubMed]

9. Cabral, H.; Makino, J.; Matsumoto, Y.; Mi, P.; Wu, H.; Nomoto, T.; Toh, K.; Yamada, N.; Higuchi, Y.; Konishi, S.; et al. Systemic Targeting of Lymph Node Metastasis through the Blood Vascular System by Using Size-Controlled Nanocarriers. ACS Nano 2015, 9, 4957-4967. [CrossRef] [PubMed]

10. Nogueira, D.R.; Tavano, L.; Mitjans, M.; Pérez, L.; Infante, M.R.; Vinardell, M.P. In vitro antitumor activity of methotrexate via $\mathrm{pH}$-sensitive chitosan nanoparticles. Biomaterials 2013, 34, 2758-2772. [CrossRef] [PubMed]

11. Sukthankar, P.; Avila, L.A.; Whitaker, S.K.; Iwamoto, T.; Morgenstern, A.; Apostolidis, C.; Liu, K.; Hanzlik, R.P.; Dadachova, E.; Tomich, J.M. Branched amphiphilic peptide capsules: Cellular uptake and retention of encapsulated solutes. Biochim. Biophys. Acta 2014, 1838, 2296-2305. [CrossRef] [PubMed]

12. Liang, J.; Wuc, W.-L.; Xub, X.-D.; Zhuo, R.-X.; Zhang, X.-Z. pH Responsive micelle self-assembled from a new amphiphilic peptide as anti-tumor drug carrier. Colloids Surf. B Biointerfaces 2014, 114, 398-403. [CrossRef] [PubMed]

13. Wang, J.; Liu, W.; Tu, Q.; Wang, J.; Song, N.; Zhang, Y.; Nie, N.; Wang, J. Folate-decorated hybrid polymeric nanoparticles for chemically and physically combined paclitaxel loading and targeted delivery. Biomacromolecules 2011, 12, 228-234. [CrossRef] [PubMed]

14. Couvreur, P.; Barrat, G.; Fattal, E.; Legrand, P.; Vauthier, C. Nanocapsule Technology: A Review. Crit. Rev. Ther. Drug Carr. Syst. 2002, 19, 99-134. [CrossRef]

15. Hilgenbrink, A.R.; Low, S.P. Folate-receptor mediated drug targeting: From therapeutics to diagnostics. J. Pharm. Sci. 2005, 94, 2135-2146. [CrossRef] [PubMed]

16. Guo, J.; Schlich, M.; Cryan, J.F.; O’Driscoll, C.M. Targeted Drug Delivery via Folate Receptors for the Treatment of Brain Cancer: Can the Promise Deliver? J. Pharm. Sci. 2017, 106, 3413-3420. [CrossRef] [PubMed]

17. Stella, B.; Arpicco, S.; Peracchia, M.T.; Desmaele, D.; Hoebeke, J.; Renoir, M.; D'Angelo, J.; Cattel, L.; Couvreur, P. Design of folic acid-conjugated nanoparticles for drug targeting. J. Pharm. Sci. 2000, 89, 1452-1464. [CrossRef]

18. Issarachot, O.; Suksiriworapong, J.; Takano, M.; Yumoto, R.; Junyaprasert, V.S. Folic acid-modified methotrexate-conjugated PEGylated poly(e-caprolactone) nanoparticles for targeted delivery. J. Nanopart. Res. 2014, 16, 2276-2290. [CrossRef]

19. Wang, C.; Cheng, L.; Liu, Y.; Wang, X.; Ma, X.; Deng, Z.; Li, Y.; Liu, Z. Imaging-Guided pH-sensitive photodynamic therapy using charge reversible up conversion nanoparticles under near-infrared light. Adv. Funct. Mater. 2013, 23, 3077-3086. [CrossRef]

20. Mello, S.B.; Tavares, E.R.; Bulgarelli, A.; Bonfa, E.; Maranhão, R.C. Intra-articular methotrexate associated to lipid nanoemulsions: Anti-inflammatory effect upon antigen-induced arthritis. Int. J. Nanomed. 2013, 8, 443-449. [CrossRef]

21. Kohler, N.; Sun, C.; Wang, J.; Zhang, M. Methotrexate-modified supermagnetica nanoparticles and their intracellular uptake into human cancer cells. Langmuir 2005, 21, 8858-8864. [CrossRef] [PubMed]

22. Yurgel, V.C.; Oliveira, C.P.; Begnini, K.R.; Schultze, E.; Thurow, H.S.; Leon, P.M.; Dellagostin, O.A.; Campos, V.F.; Beck, R.C.R.; Guterres, S.S.; et al. Methotrexate diethyl ester-loaded lipid-core nanocapsules in aqueous solution increased antineoplastic effects in resistant breast cancer cell line. Int. J. Nanomed. 2014, 9, 1583-1591. [CrossRef] 
23. Bender, E.A.; Cavalcante, M.F.; Adorne, M.D.; Colomé, L.M.; Guterres, S.S.; Abdalla, D.S.P.; Pohlmann, A.R. New strategy to surface functionalization of polymeric nanoparticles: one-pot synthesis of $\mathrm{scFv}$ anti-LDL(-)-functionalized nanocapsules. Pharm. Res. 2014, 31, 2975-2987. [CrossRef] [PubMed]

24. Oliveira, C.P.; Prado, W.A.; Lavayen, W.; Büttenbender, S.L.; Beckenkamp, A.; Martins, B.S.; Lüdtke, D.S.; Campo, L.F.; Rodembusch, F.S.; Buffon, A.; et al. Bromelain-functionalized multiple-wall lipid-core nanocapsules: Formulation, chemical structure and antiproliferative effect against human breast cancer cells (MCF-7). Pharm. Res. 2017, 34, 438-452. [CrossRef] [PubMed]

25. Ma, J.; Jemal, A. Breast cancer statistics. In Breast Cancer Metastasis and Drug Resistance, 1st ed.; Ahmad, A., Ed.; Springer: New York, NY, USA, 2013; pp. 1-8. ISBN 978-1-4614-5647-6.

26. Boing, A.F.; Vargas, S.A.L.; Boing, A.C. A carga das neoplasias no Brasil: Mortalidade e morbidade hospitalar entre 2002-2004. Rev. Assoc. Med. Bras. 2007, 53, 317-322. [CrossRef] [PubMed]

27. Guiu, S.; Michiels, S.; Andre, F.; Cortes, J.; Denkert, C.; Di Leo, A.; Hennessy, B.T.; Sorlie, T.; Sotiriou, C.; Turner, N.; et al. Molecular subclasses of breast cancer: How do we define them? The IMPAKT 2012 Working Group Statement. Ann. Oncol. 2012, 23, 2997-3006. [CrossRef] [PubMed]

28. Mendonça, M.A.; Cunha, F.Q.; Murta, E.F.; Tavares-Murta, B.M. Failure of neutrophil chemotactic function in breast cancer patients treated with chemotherapy. Cancer Chemother. Pharm. 2006, 57, 663-670. [CrossRef] [PubMed]

29. Shapira, A.; Livneya, Y.D.; Broxtermanc, H.J.; Assaraf, Y.G. Nanomedicine for targeted cancer therapy: Towards the overcoming of drug Resistance. Drug Resist. Updat. 2011, 14, 150-163. [CrossRef] [PubMed]

30. Banerjee, D.; Mayer-Kuckuk, P.; Capiaux, G.; Budak-Alpdogan, T.; Gorlick, R.; Bertino, J.R. Novel aspects of resistance to drugs targeted to dihydrofolate reductase and thymidylate synthase. Biochim. Biophys. Acta 2002, 1587, 164-173. [CrossRef]

31. Selga, E.; Oleaga, C.; Ramírez, S.; Almagro, M.C.; Noé, V.; Ciudad, C.J. Networking of differentially expressed genes in human cancer cells resistant to methotrexate. Genome Med. 2009, 1, 83-99. [CrossRef] [PubMed]

32. Lebret, V.; Raehm, L.; Durand, J.-O.; Smaïhi, M.; Werts, M.H.V.; Blanchard-Desce, M.; Méthy-Gonnod, D.; Dubernet, C. Surface functionalization of two-photon dye-doped mesoporous silica nanoparticles with folic acid: Cytotoxicity studies with HeLa and MCF-7 cancer cells. J. Sol-Gel Sci. Technol. 2008, 48, 32-39. [CrossRef]

33. Oliveira, C.P.; Venturini, C.G.; Donida, B.; Poletto, F.S.; Guterres, S.S.; Pohlmann, A.R. An algorithm to determine the mechanism of drug distribution in lipid-core nanocapsule formulations. Soft Matter 2013, 9 , 1141-1150. [CrossRef]

34. Cé, R.; Marchi, J.G.; Bergamo, V.Z.; Fuentefria, A.M.; Lavayen, V.; Guterres, S.S.; Pohlmann, A.R. Chitosan-coated dapsone-loaded lipid-core nanocapsules: Growth inhibition of clinical isolates, multidrug-resistant Staphylococcus aureus and Aspergillus ssp. Colloids Surf. A Physicochem. Eng. Asp. 2016, 511, 153-161. [CrossRef]

35. Kang, M.J.; Park, S.H.; Kang, M.H.; Park, M.J.; Choi, Y.W. Folic acid-tethered Pep-1 peptide-conjugated liposomal nanocarrier for enhanced intracellular drug delivery to cancer cells: Conformational characterization and in vitro cellular uptake evaluation. Int. J. Nanomed. 2013, 8, 1155-1165. [CrossRef]

36. Chintamani; Singhal, V.; Singh, J.P.; Lyall, A.; Saxena, S.; Bansal, A. Is drug-induced toxicity a good predictor of response to neoadjuvant chemotherapy in patients with breast cancer?-A prospective clinical study. BMC Cancer 2004, 4, 48. [CrossRef] [PubMed]

37. Zhou, S.; Li, Y.; Cui, F.; Jia, M.; Yang, X.; Wang, Y.; Xie, L. Development of multifunctional folate-poly(ethylene glycol)-chitosan-coated $\mathrm{Fe}_{3} \mathrm{O}_{4}$ nanoparticles for biomedical applications. Macromol. Res. 2014, 22, 58-66. [CrossRef]

38. Xiang, G.; Wu, J.; Lu, Y.; Liu, Z.; Lee, R.J. Synthesis and evaluation of a novel ligand for folate-mediated targeting liposomes. Int. J. Pharm. 2008, 356, 29-36. [CrossRef] [PubMed]

39. Pan, J.; Liu, Y.; Feng, S.-S. Multifunctional nanoparticles of biodegradable copolymer blend for cancer diagnosis and treatment. Nanomedicine 2010, 5, 347-350. [CrossRef] [PubMed]

40. Murawala, P.; Tirmale, A.; Shiras, A.; Prasad, B.L.V. In situ synthesized BSA capped gold nanoparticles: Effective Carrier of anticancer drug methotrexate to MCF-7 breast cancer cells. Mater. Sci. Eng. C Mater. Biol. Appl. 2014, 34, 158-167. [CrossRef] [PubMed] 
41. Zanotto-Filho, A.; Coradini, K.; Braganhol, E.; Schröder, R.; Oliveira, C.M.; Simões-Pires, A.; Battastini, A.M.O.; Pohlmann, A.R.; Guterres, S.S.; Forcelini, C.M.; et al. Curcumin-loaded lipid-core nanocapsules as a strategy to improve pharmacological efficacy of curcumin in glioma treatment. Eur. J. Pharm. Biopharm. 2013, 83, 156-167. [CrossRef] [PubMed]

42. Bhattacharya, R.; Patra, C.R.; Earl, A.; Wang, S.; Katarya, A.; Lu, L.; Kizhakkedathu, J.N.; Yaszemski, M.J.; Greipp, P.R.; Mukhopadhyay, D.; et al. Attaching folic acid on gold nanoparticles using noncovalent interaction via different polyethylene glycol backbones and targeting of cancer cells. Nanomedicine 2011, 3, 224-238. [CrossRef]

43. Filipe, V.; Hawe, A.; Jiskoot, W. Critical Evaluation of Nanoparticle Tracking Analysis (NTA) by NanoSight for the Measurement of Nanoparticles and Protein Aggregates. Pharm. Res. 2010, 27, 796-810. [CrossRef] [PubMed]

44. Sartori, T.; Seigi Murakami, F.; Pinheiro Cruz, A. Machado de Campos, A. Development and validation of a fast RP-HPLC method for determination of methotrexate entrapment efficiency in polymeric nanocapsules. J. Chromatogr. Sci. 2008, 46, 505-509. [CrossRef] [PubMed]

(C) 2018 by the authors. Licensee MDPI, Basel, Switzerland. This article is an open access article distributed under the terms and conditions of the Creative Commons Attribution (CC BY) license (http://creativecommons.org/licenses/by/4.0/). 